Journal of the Scholarship of Teaching and Learning, Vol. 21, No. 1, April 2021, pp. 320-362.

doi: 10.14434/josotl.v21i1.30101

\title{
Creating More Inclusive Research Environments for Undergraduates
}

\author{
Heather Haeger \\ California State University, Monterey Bay \\ hhaeger@csumb.edu \\ Corin White \\ California State University, Monterey Bay \\ Shantel Martinez \\ California State University, Monterey Bay \\ Selena Velasquez \\ California State University, Monterey Bay
}

\begin{abstract}
Although there are numerous evidence-based benefits to undergraduate research for newmajority students (students who are from traditionally underrepresented ethnicities, first-generation college students, students from lower-income families, or transfer students) (Hurtado, S. et al., 2011; Kinqie et al., 2008a; Lopatto, 2007), they are less likely to participate or stay in mentored research experiences (Finley \& McNair, 2013; Haeger et al., 2015). In order to determine not only who has access to undergraduate research, but to also identify what barriers to full-inclusion exist for newmajority students, we conducted a mixed methods study at a public, Hispanic Serving Institution. We analyzed institutional data to explore who participates in research and who does not. We also specifically sampled a group of students who expressed an interest in research experiences but who never actually participated for our student survey ( $N=96)$. Additionally, we conducted five focus groups with students, staff, and faculty $(\mathrm{N} \sim 30)$. We found positive results in the analysis of patterns of participation and found no significant or substantial differences between students who did or did not participate in undergraduate research in terms of race/ ethnicity, gender, or first-generation status. The undergraduate researcher population did have significantly more STEM majors and Pell grant recipients. The qualitative analysis identified barriers to participation in research in the following areas: access to research opportunities, programmatic structures, research culture and norms, and campus climate. We present these findings along with descriptions of initiatives that have been successful in diversifying research participation and strategies to create more inclusive research environments.
\end{abstract}

Keywords: inclusivity, undergraduate research, engagement, first-generation college students, traditionally underrepresented minority, new-majority, low-income

The increasing diversity of the U.S. population and population of students in higher education inspires a national call that highlights the need to focus on equity and inclusion in undergraduate research (UR) (National Academies of Sciences, Engineering and Medicine, 2017), both as a social justice issue and in order to prepare students for careers and graduate education, particularly in STEM (Estrada, Hernandez, \& Shultz, 2018; National Math + Science, 2010). Undergraduate research, a wellestablished high-impact practice, provides significant benefits for new-majority students (students who are from traditionally underrepresented ethnicities, the first in their family to go to college, from 
lower-income families, and transfer students) (Jones, Barlow, \& Villarejo, 2010; Kinzie, Gonyea, Shoup, \& Kuh, 2008; Villarejo, Barlow, Kogan, Veazey, \& Sweeney, 2008). However, new-majority students are less likely to participate in UR than their peers (National Academy of Sciences, National Academy of Engineering, \& Institute of Medicine, 2011), even when attending Minority Serving Institutions (MSI) (Haeger, BrckaLorenz, \& Webber, 2015). Additionally, when participating in research, new-majority students may find a research culture that is an unsupportive or hostile environment (Clancy, Nelson, Rutherford, \& Hinde, 2014).

To explore who has access to research opportunities and to identify potential barriers to participation for new-majority students, we conducted a mixed-methods study at a public, primarily undergraduate, Hispanic Serving Institution (HSI). The diverse student body and established research programs provide an opportunity to contribute to the literature on undergraduate research, which is dominated by studies at Predominantly White Institutions (PWI). As of Fall 2020, the institution had a population of 7,616 students comprised of $62 \%$ women, $38 \%$ men, and less than .01\% non-binary students (CSUMB IAR, 2019). More than half the student population is an underrepresented minority (URM): 44\% Latino/a, 8\% two or more races, 4\% African American, 1\% Native American, and 1\% Pacific Islander (CSUMB IAR, 2019). In addition, 51\% of students were the first in their family to go to college, and 32\% were low-income (Pell Grant eligible) (CSUMB IAR, 2019). The institution also has a centralized undergraduate research office-the Undergraduate Research Opportunities Center (UROC)—which supports (financially and professionally through its multiple programs) undergraduates of all disciplines and at various stages of the research process.

Our mixed-methods study utilized institutional data, surveys, and focus groups to address the following research questions:

1. Representation: How does the demographic and disciplinary background of undergraduate researchers reflect or differ from the general student population and from other students who are interested in research but do not actually participate?

2. Inclusivity: What are the programmatic, cultural, and environmental barriers to newmajority student participation in research as identified by students, faculty, and staff?

This article will answer these questions and will discuss the implications of this research using an interactional model of inclusivity. We also present responses/strategies to move towards full inclusion in UR.

\section{Conceptual Framework}

We conceptualize inclusivity as a continuum instead of a dichotomous "inclusive" or "exclusive" environment while recognizing that experiences of inclusivity are not monolithic. An environment which is inclusive and supportive for some students may be exclusive for others. Additionally, mesosystems within universities, such as policies, programs, and structures, interact to shape students' social interactions and sense of belonging (Kilanowski, 2017). Our research will examine how inclusive the environment is and to whom it is inclusive through an interactional model of social and environmental factors (Figure 1) adapted from BrckaLorenz, Duran, and Haeger (2020). In this model,

Journal of the Scholarship of Teaching and Learning, Vol. 21, No. 1, April 2021. josotl.indiana.edu 
we examine how university culture, structures, policies, and programs intersect and interact in order to create more inclusive or exclusive environments. ${ }^{1}$

\section{Research Environment}

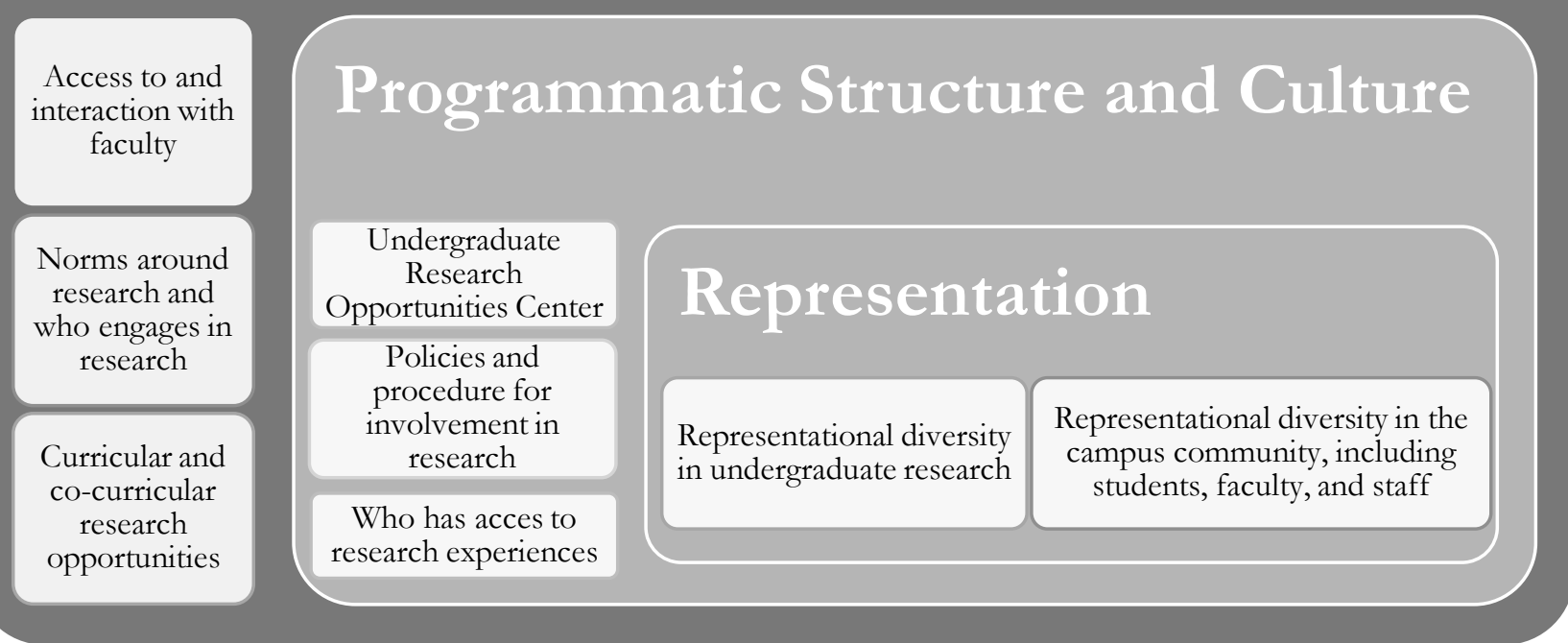

Figure 1: Conceptual Model of Inclusivity. Intersectional levels of inclusivity starting with representation, then programmatic structure and culture, both within the larger campus research environment.

\section{Representation}

The foundation of an inclusive environment is representation, meaning how representative is the population of researchers when compared to the student population. Issues of underrepresentation are a significant problem in UR (Haeger et al., 2015; Kinzie et al., 2008b) with significantly fewer students of color, first-generation, low-income, and transfer students participating in undergraduate research, even at Minority Serving Institutions. This is a critical equity gap in access to undergraduate research, but we also need to look beyond representation and examine inclusivity in terms of programmatic structures, research environments, and campus research culture.

\footnotetext{
${ }^{1}$ In this paper, the authors are encouraging a paradigmatic shift away from the term 'diversity' with regards to identifying and building more equitable opportunities for students engaging in undergraduate research. Rather, we offer the term, 'inclusion' in its place due to its move towards intersectionality (Crenshaw, 1991; Collins \& Bilge, 2016) and belongingness. In line with other scholars, we critique the term 'diversity' as it often obscures systematic, historical, and oppressive power structures, while upholding marketplace values and neoliberal constructions of race, ethnicity, gender, sexuality, ability, citizenship, etc. As such, the term 'diversity' frequently is institutionally utilized to invoke 'difference', yet simultaneously blurs 'difference' and fails to evoke a commitment to action or change. For further literature, please see Ahmed, 2012; Alexander, 2005; Ali, 2009; Anzaldúa \& Keating, 2009; Deem \& Ozga, 1997; Mohanty, 2003; and Puwar, 2004.
} 


\section{Programs}

Undergraduate research programs support retention (Sweeney \& Villarejo, 2013), foster career development (Chang, Sharkness, Hurtado, \& Newman, 2014), and develop self-efficacy (Robnett, Chemers, \& Zurbriggen, 2015), but research has not examined how programmatic structures create or limit access to research. We examine representation on a campus that has taken numerous steps to increase inclusion in research, allowing us to understand if such programmatic interventions have increased student access. In addition, we advance the conversation by including qualitative data to give voice to students' experiences and gain insight into why they did or did not participate.

\section{Research Environment}

Historically, research is an exclusive environment (Milem, Chang, \& Lising Antonio, 2005). Students have to be invited into research or granted access by someone in a position of power (e.g., faculty or graduate student), meaning that students are operating in relationships where they often have the least valued knowledge and perspective, least ownership or belonging to that space, and least powerful position in the relationship (Hurtado, Tran, \& Chang, 2011). This social context is crucial to consider when understanding the context in which students gain access to research opportunities and how they navigate those experiences.

\section{Methods}

We conducted a multi-phased, mixed-methods study at a diverse 4-year, public institution from 20172019. The study was submitted to the Institutional Review Board (IRB) as protocol number 16-033. The IRB determined the study did not meet the federal definition of human subject research (Part 56 of the 21 Code of Federal Regulations and Part 46 of the 45 Code of Federal Regulations); therefore, the project does not require the Committee for the Protection of Human Subjects (CPHS) approval. This determination was made because the data was collected and analyzed as quality improvement activities to improve access to and support of undergraduate research and did not involve systematic testing of a new intervention (45 CFR 46.102(d)). Even though the study did not require CPHS approval, we have taken extra precautions to conduct this study ethically while protecting participant anonymity. We collected limited identifiers (consent forms) for survey and focus group participants, and the lead researcher permanently de-identified all data before analysis and before data was made available to other members of the research team. Researchers also completed the following CITI trainings: Humans Subjects in Research, Responsible Conduct of Research (Social Sciences), and Family Educational Rights and Privacy Act (FERPA).

The study was conducted in three phases (Figure 2). To examine representation as the first phase, we first identified students who had not participated in research, yet expressed interest in research (interested students). We operationalized "interest" as attending a meeting or workshop focused on finding research opportunities. Next, we cross-referenced this list of students with the list of students who participated in research through UROC to find the group of interested nonparticipators. Mean comparisons on institutional data were used to test the difference in representation between UR and interested students in terms of gender, race/ethnicity, Pell eligibility, parental education (first-generation in college), GPA, class standing, and major. We were able to identify 112 interested students (students who expressed an interest in research between September, 2016 and February, 2017 but who did not participate in research on campus).

Journal of the Scholarship of Teaching and Learning, Vol. 21, No. 1, April 2021. josotl.indiana.edu 


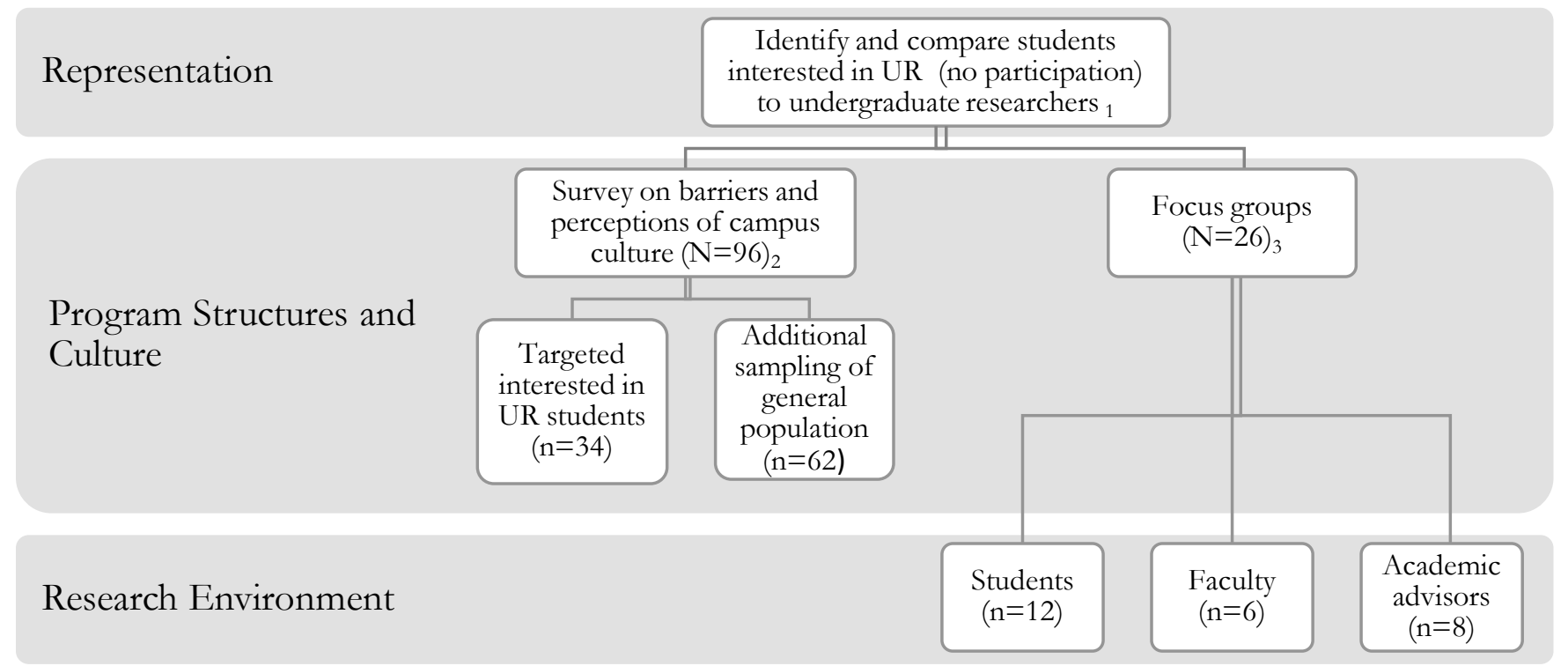

Figure 2: Data Collection within Intersectional Model of Inclusivity. Institutional data on representation. Survey and qualitative data on programmatic and research environment.

To create a comparison group, we identified students who did not participate in research despite expressing an interest in finding research opportunities. We operationalized interest in research as attending workshops about finding research opportunities or scheduling meetings with UROC staff to learn about research opportunities. Surveys were first targeted to these interested non-participators with a 30\% response rate, but additional sampling from the general population was used to increase the sample and capture diverse student experiences.

To move beyond numerical representation, we also surveyed the 112 interested students with a $30 \%$ response rate. To increase the sample, we sent out an email to students who had signed up for information about research through the UROC email list, student clubs, and sports teams ( $\mathrm{N}=96)$. The survey asked students about their knowledge of research opportunities, their educational and career aspirations, interaction with staff and faculty, and information channels on campus. Students were also asked questions about the norms and culture of research and barriers that might prevent participation in research.

The third phase of the research involved conducting focus groups with academic advisors, faculty, and students. All academic advisors on campus were invited to participate in the focus group, and $50 \%$ of them participated in one of the two focus groups for a total of eight participants. Faculty were recruited from a faculty working group on mentoring, which included many faculty who mentored students in research. All six faculty in the working group participated in the focus group. Since these faculty were actively engaged in thinking about how to better support and mentor students, they provided a key perspective on mentoring in research, and future research should consider sampling faculty who may be less engaged in research mentoring or who have specifically chosen not to mentor students to further understand barriers to participation in research. Participants for the student focus group were recruited by emailing the survey respondents and through fliers on campus. The majority of students in the focus groups had not participated in mentored research experiences or course-based research experiences. Students who responded to the flier and attended a focus group despite having participated in research were still included in the study and provided useful information about barriers they had to overcome in order to participate in research. 
Focus group protocols were informed by previous literature and by issues that were brought up in the survey. All of the focus groups discussed questions about the definition of research, who participated in research, the availability of research opportunities on campus, and barriers for participation in research. Student focus groups discussed questions about direct experiences. Faculty and advisor focus groups discussed direct experiences in mentoring students in research or helping students find research opportunities and perceptions of barriers for students. Focus groups were transcribed and coded for emergent themes. Two researchers coded and created memos on each focus group. The research team met weekly to discuss the coding structure and to resolve any differences in interpretation. Themes were then organized and used to develop our conceptual framework for inclusivity (Figure 1).

\section{Findings}

The institution represents a unique sample because of the campus diversity and initiatives to increase inclusivity in undergraduate research. We have not tested the impact of any specific intervention, but instead have examined whether the summative impact of these systematic interventions increased inclusivity in research for undergraduates.

\section{Representation}

We found no significant or substantial differences between undergraduate researchers and students who did not participate in undergraduate research in terms of parental education or race/ethnicity (see Figures 3 and 4).

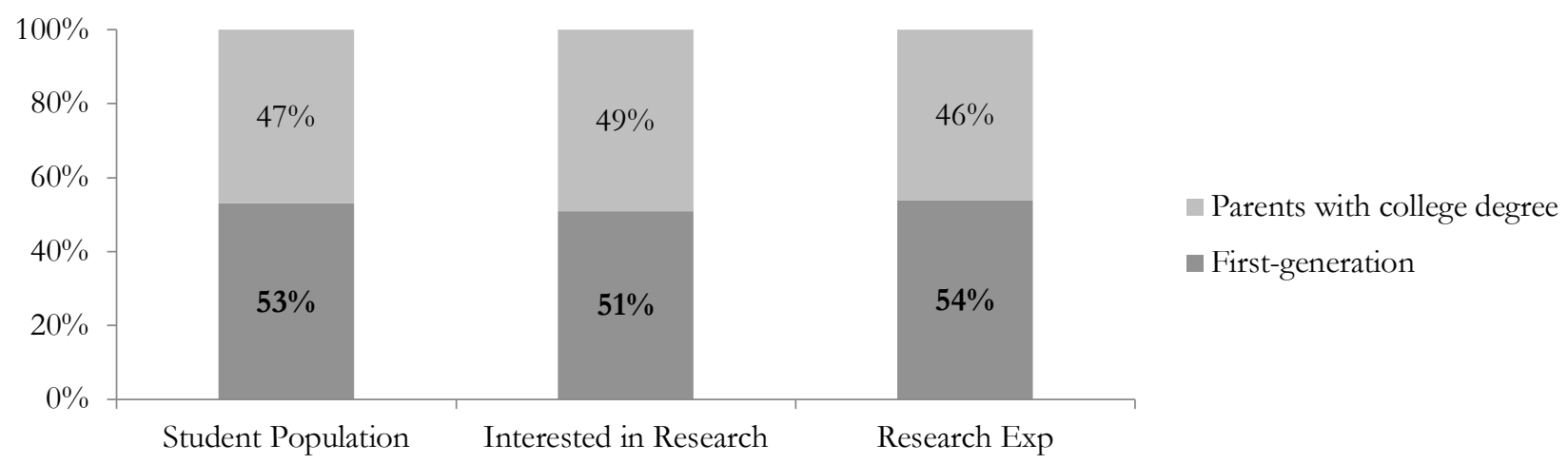

Figure 3: Comparison of Parental Education. Comparing proportion of first-generation undergraduate researchers to the general student population and students interested in research.

A significantly higher proportion of undergraduate researchers were from a low-income family (as measured by Pell Grant eligibility); 54\% of undergraduate researchers were Pell-eligible compared to $38 \%$ of interested students and $36 \%$ of the general student population $(p<.001$, Figure 4$)$. 


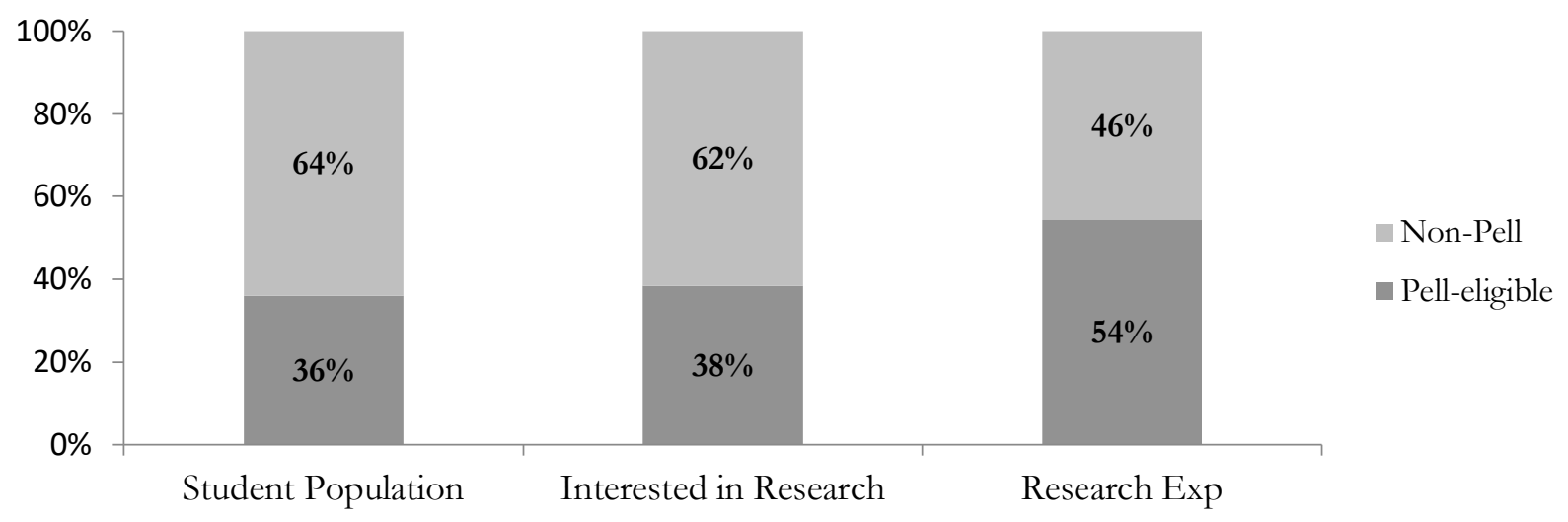

Figure 4: Comparison of Low-income/Pell-eligible Students. Comparing the proportion of Pell eligible undergraduate researchers to the general student population and interested-students.

The proportion of students of color in research (45\% URM) is somewhat lower than interested students (54\% URM) and the general student population (57\% URM) (Figure 5).

Though national trends, even at other MSI's, suggested continued patterns of unequal participation in undergraduate research, we found that the population of undergraduate researchers was more diverse than the general student population in terms of income level and parental education, but slightly less diverse in terms of race. The majority of undergraduate researchers were the first in their family to go to college, Pell-eligible, and/or from a race/ethnicity traditionally underrepresented in higher education.

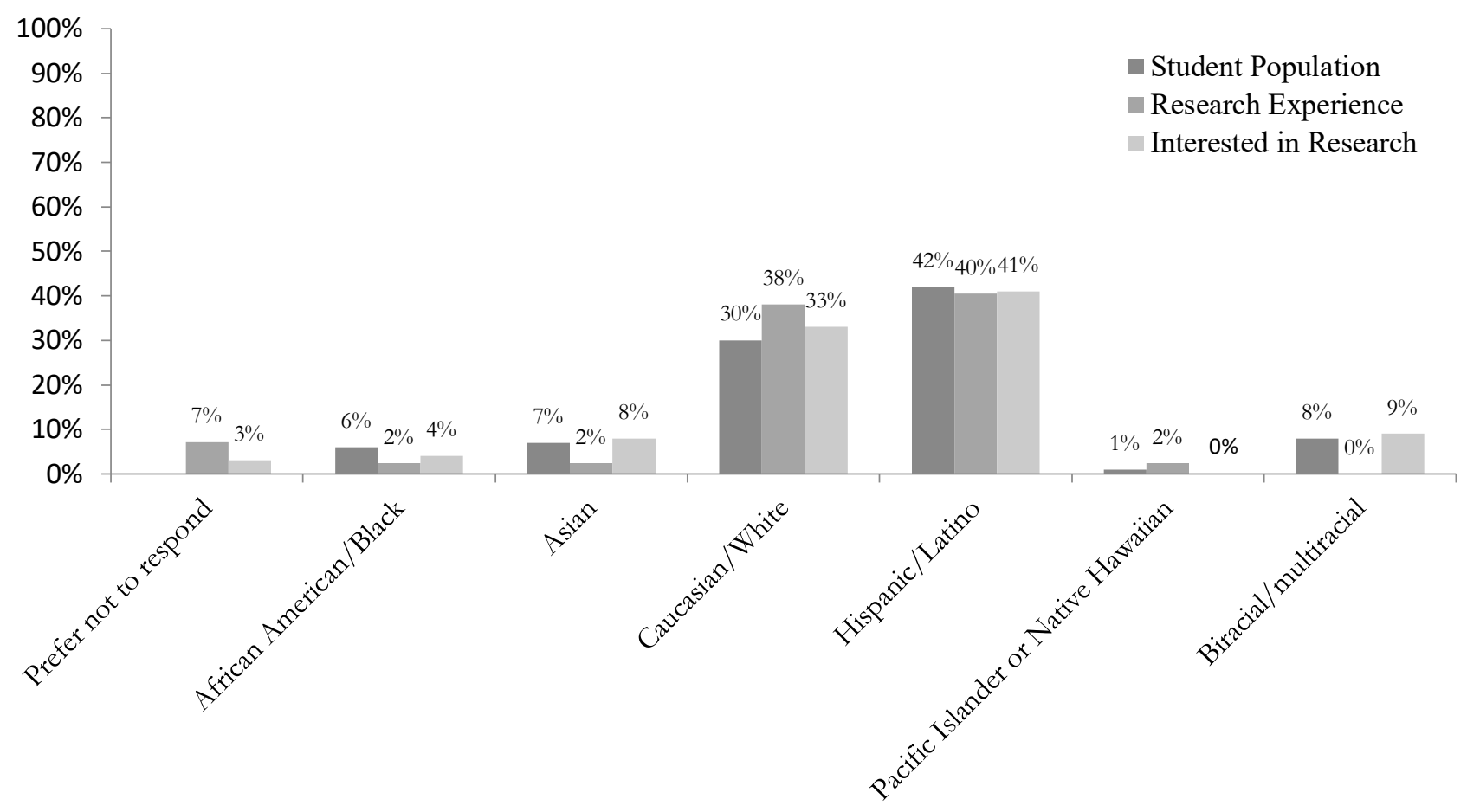

Figure 5: Comparison of Race/Ethnicity. Proportion of undergraduate researchers, general student population, and interested students by race/ethnicity. 
Though the majority of undergraduate researchers were the first in their family to go to college, from lower-income households, and were students of color, this was not reflected in faculty and advisor perceptions. Faculty and advisors stated in the focus groups that they thought fewer firstgeneration college students knew about the value of research or how to get involved in research experiences. A science faculty noted: "First-gen students don't know what research is or why it's beneficial to them. Too esoteric to them" (Faculty focus group). Advisors also brought up concerns that the lack of diversity in faculty mentors would lead to fewer students of color participating in research:

A student who is a first-generation, person of color and they don't see that representation, they are going to turn away. Then faculty also play a role in hindering a student's opportunity to really reach their full potential as someone who would want to be a researcher. So I think that inclusion is very important especially with the population of students that we have here, yeah diversity and inclusion. (Advisor focus group).

Similarly, students brought up how their background made getting involved in research more difficult, as this interested student wrote:

I come from a family of Mexican immigrant (now citizens) laborers. They came here with nothing and without a proper education. We grew up in a low income status... so my options were limited. Knowing that I did not have any family in research let alone in college made that bridge to research even harder. For someone like me I have had to have had a lot of ambition, motivation and guts to get to where I am right now, but that is a lot easier said [than] done. (Student survey).

These sentiments from students, faculty, and staff illustrate the intersections of race and class, and that even when numerical representation is achieved, students can still experience barriers that make participating in research more difficult.

\section{Programmatic Structure and Culture}

The vast majority $(76 \%)$ of students had heard about undergraduate research opportunities on campus, with the majority of students hearing about research through professors $(72 \%)$ or from the UROC (68\%) (Figure 6). "Other" responses included: emails, Equal Opportunity Program (EOP), flyers, and the university search engine.

Journal of the Scholarship of Teaching and Learning, Vol. 21, No. 1, April 2021.

josotl.indiana.edu 


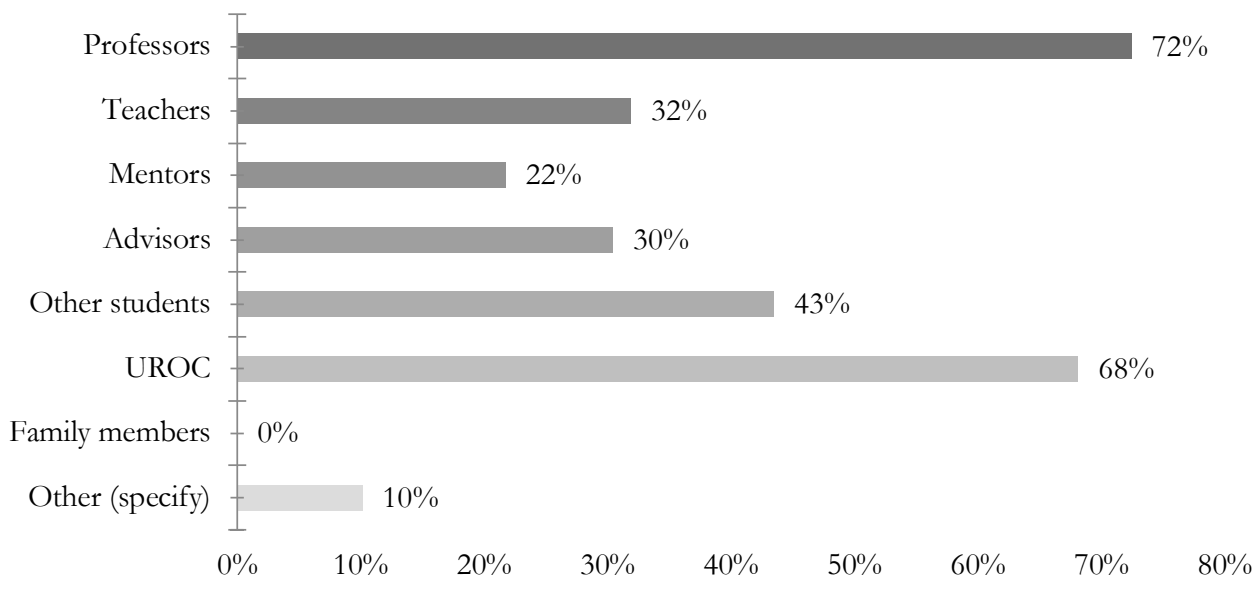

Figure 6: Information Channels. Students reporting where they learned about research opportunities.

A large majority of students believe that research would be helpful for their future goals (Figure 7). The fact that 94\% of students think that UR would be or might be helpful for them, but that the majority do not participate in research, suggests a need to increase access to research opportunities.

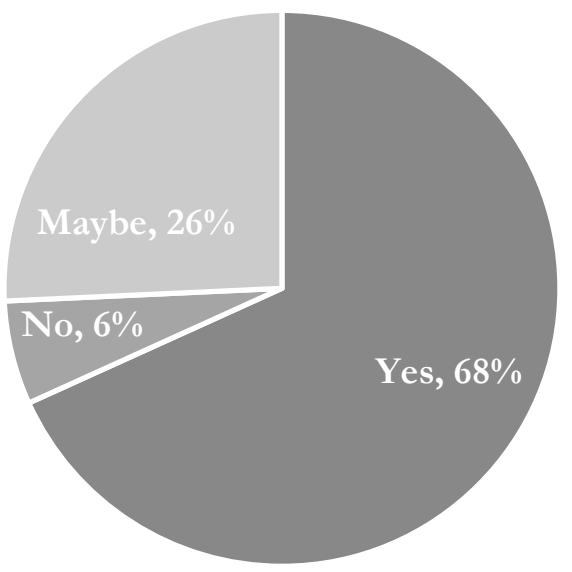

Figure 7: Would undergraduate research help you in your career goals? Students reporting if research would help them in their careers.

Some of the most common reasons for students not participating in research despite seeing it as valuable were logistical and related to confusing program structures and policies. Navigating academic structures, such as finding and applying for research opportunities, is confusing for students. The institution is unique in that many of the mentored research opportunities are funded (paid hourly); however, many students said that they could not afford to participate in research in terms of time or 
money and were unaware of paid research opportunities. Many students in the survey (51\%) brought up economic barriers that prevented them from participating in research. Most explicitly, students discussed two economic barriers: difficulty in finding paid research opportunities and not having enough time to participate in unfunded research experiences because they had to work. This can be seen in a student's discussion of why they did not participate in research:

A lot of these opportunities do not pay and a lot of students need money... Pay limits on how many hours a student can work also take away from the ability of students to provide for themselves, forcing them to choose other jobs. (Student survey).

Students also noted that taking care of family members and long commute times made it more challenging to participate in research.

Another significant barrier was finding a faculty mentor. Structural barriers, such as not taking classes in their major the first couple years of college or being a transfer student, meant that many students did not interact with tenure track faculty in their major until they were upper-division students, which made finding research opportunities before they graduated difficult. We found that the majority (61\%) of interested students were seniors and that an additional $29 \%$ were juniors when they expressed interest in research. Interested students had completed an average of 95 units (with an additional 15 units in progress), so limited time left in their undergraduate career may have influenced why they did not participate in research. A student noted that students may not have access to tenure track faculty in their discipline until they are in upper division courses:

It seems, you need to know someone in order to participate in the research. My challenge is [I] needed a science mentor when I haven't started my science course yet. So I feel behind the curve because I plan to take those science courses my final semester which wouldn't allow enough time for me to gain a mentor/relationship with a professor in order to be mentored through research. (Student survey response).

The underrepresentation of lower-division and recent transfer students is also related to university structures that affect when students are able to take classes and connect with tenure track faculty in their major.

The challenge of connecting with faculty in their discipline before they were in their last semester or two was even more pronounced for transfer students. An upper-division transfer student in the focus group stated that research "is not accessible to me as a transfer [student]; as soon as you step on campus you have to apply to UROC" (Student survey). Even when students had engaged in research at their community college, they found it difficult to participate in research after transferring to a four-year institution, as this student discusses:

There are students like myself who have been heavily involved with research at their community college and are transferring with the hope of doing more things like that ... Being a transfer student made taking advantage of [a research] opportunity very difficult as well as being a financially independent student working two jobs. I was unable to plan for this opportunity when I transferred because my focus had to be on acquiring work. When transferring, I didn't know this [paid research] was an option. (Student survey).

Furthermore, approaching faculty about their research or available research opportunities was intimidating for students at all levels. One student who was not able to participate in research, despite wanting to, explained why the current system did not "work out" for her: 
I did not know how to ask for research. I did not know what it was. I knew I wanted to start participating in Research, but I feel like prior exposure or volunteering in projects would help fill that gap for students like myself. Maybe collaborating with professors who are on campus looking for students to participate on their projects would help students know what research is and create that bridge to undergraduate research. I know there are professors who could use help from undergraduates and I know they do not really do outreach at least not with UROC from what I remember. Collaborating with professors on these types of projects would better increase student participation in research at [the university] and help it be more diverse as well. (Student survey).

Many students expressed an interest in a centralized listing of research opportunities or even of faculty research interests. Even though many faculty list prior research and current projects in their profiles, students found this system difficult to navigate and felt too intimidated to email faculty they did not know. Students repeatedly asked for a centralized place to look for open research projects or information about faculty who are willing to work with undergraduate researchers. Students were also interested in opportunities to interact with faculty or resources on how to talk to faculty about research.

\section{Research Environment}

Approximately $25 \%$ of the student respondents discussed barriers related to research as an exclusive environment. Students felt that UROC and faculty research centers/labs were intimidating spaces where they did not belong:

Although UROC is an amazing program I would love to see it become better. From a personal experience the current system feels like it is catered more to students who do have the privilege of coming from some sort of scientific background and I think this program could do better to introduce research experiences to students who do not come from that background. (Student survey).

This student further clarified that the "scientific background" they were referring to included having family or other role models who had gone to college or been involved in research before.

Similarly, many students stated that research was not for them and/or that research was only for students who "had it all together." This idea of students who "had it all together" was often conceptualized as students who were in STEM majors, had high GPAs, and/or had solidified their academic and career goals. One survey respondent stated that she thought the main reason more students didn't participate in research was "The mindset that only straight-A students will be successful at research" (Student survey). Undergraduate researchers did have slightly higher GPAs than interested students (3.4 UR vs. 3.2 interested-students), although the actual difference (0.2 points) was much smaller than the difference perceived by students. Faculty and advisors similarly thought that many students did not feel like they belonged in research because they did not see themselves as competent enough to engage in research.

The idea of who belonged in research and who should participate in research came up frequently, especially related to which disciplines offered research experiences for undergraduates and what type of student participates. There was not a significant disciplinary difference between researchers and interested students, but both interested students and researchers had a much higher proportion of STEM majors $(\mathrm{p}<.001)$. The majority of both undergraduate researchers $(64 \%)$ and interested students $(72 \%)$ were in STEM majors compared to only $21 \%$ of the general student

Journal of the Scholarship of Teaching and Learning, Vol. 21, No. 1, April 2021. josotl.indiana.edu 
population. Students also expressed the perception that research and UROC programs were intended for high-achieving STEM students. As one student stated:

[Information about research] didn't apply to me. If you are not a science or STEM major, ...UROC is STEM oriented. In the World Languages buildings and Humanities buildings there are no representations of UROC. (Student focus group).

Similarly, when we asked faculty about who participated in undergraduate research on campus, they noted "social sciences and humanities [students] don't see how they fit in UROC. Think it doesn't really apply to them" (Faculty focus group). Students also brought up broader ideas about social or cultural inclusion in research. When asked who typically participates in research, this student responded:

At first, I always thought a lot of socially awkward people in white lab coats. When I interned at Adobe's research lab for my internship during Summer 2017, it changed my perspective of what $\mathrm{PhD}$ computer scientists do. It just feels like a very advanced school project that they have a lot of choice in deciding what to work on. I made friends and had a fun summer. (Student survey).

Students, faculty, and advisors all brought up the idea that students who already had clear educational or professional goals were more likely to participate in research than students who were still deciding on a major or career path. One student who mentioned that the idea of participating in research was too intimidating for him also described "typical" undergraduate researchers as "Highly motivated students who are on a path to graduate school" (Student survey). In congruence, undergraduate researchers did report higher educational aspirations than non-researchers, and significantly more researchers aspired to go to graduate school $(\mathrm{p}<.001)$ (Figure 8$)$. The vast majority $(82 \%)$ of undergraduate researchers aspire to go to graduate school, with $52 \%$ aspiring to earn a doctorate degree. In contrast, $52 \%$ of students who had not conducted research aspired to go to graduate school, and only $23 \%$ aspired to a doctorate. Additionally, $23 \%$ of the non-researchers were undecided about their educational aspirations compared to only $7 \%$ of undergraduate researchers.

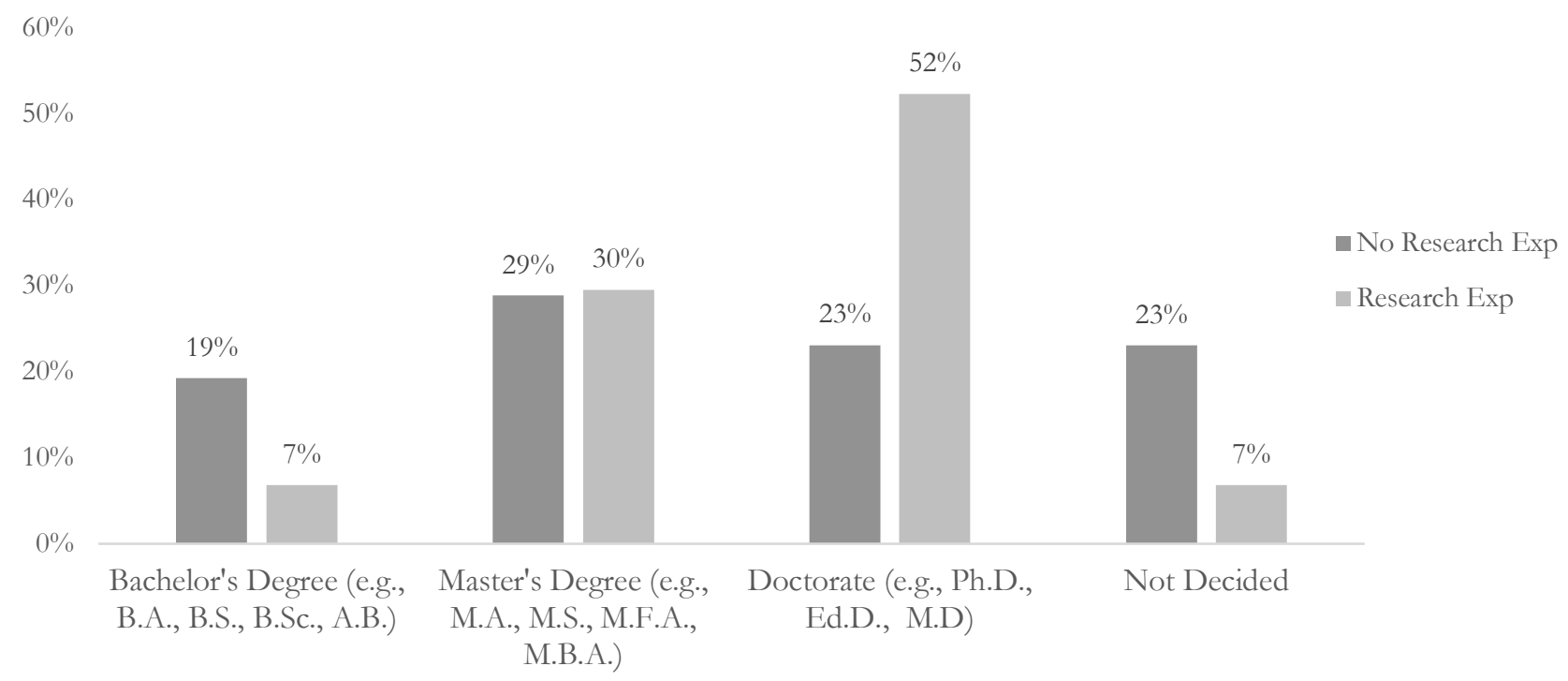

Figure 8: Educational Aspirations. Comparison between highest degree aspired to for undergraduate researchers and students without research experience. 
As some of the students pointed out, it may be that students who have higher aspirations seek out research, but faculty also brought up that research helps students refine their educational aspirations.

\section{Discussion}

We have conducted a mixed-methods study in order to explore UR representation and UR inclusivity for new majority students at a diverse and predominantly undergraduate institution. In this section, we will discuss the implications of our findings and highlight responses UROC and others have implemented in order to address the identified barriers. The discussion and responses are organized within our conceptual framework (Figure 9) in order to strategize intervention, increase representation, evaluate program structure and culture, and, ultimately, create more inclusive research environments for undergraduates.

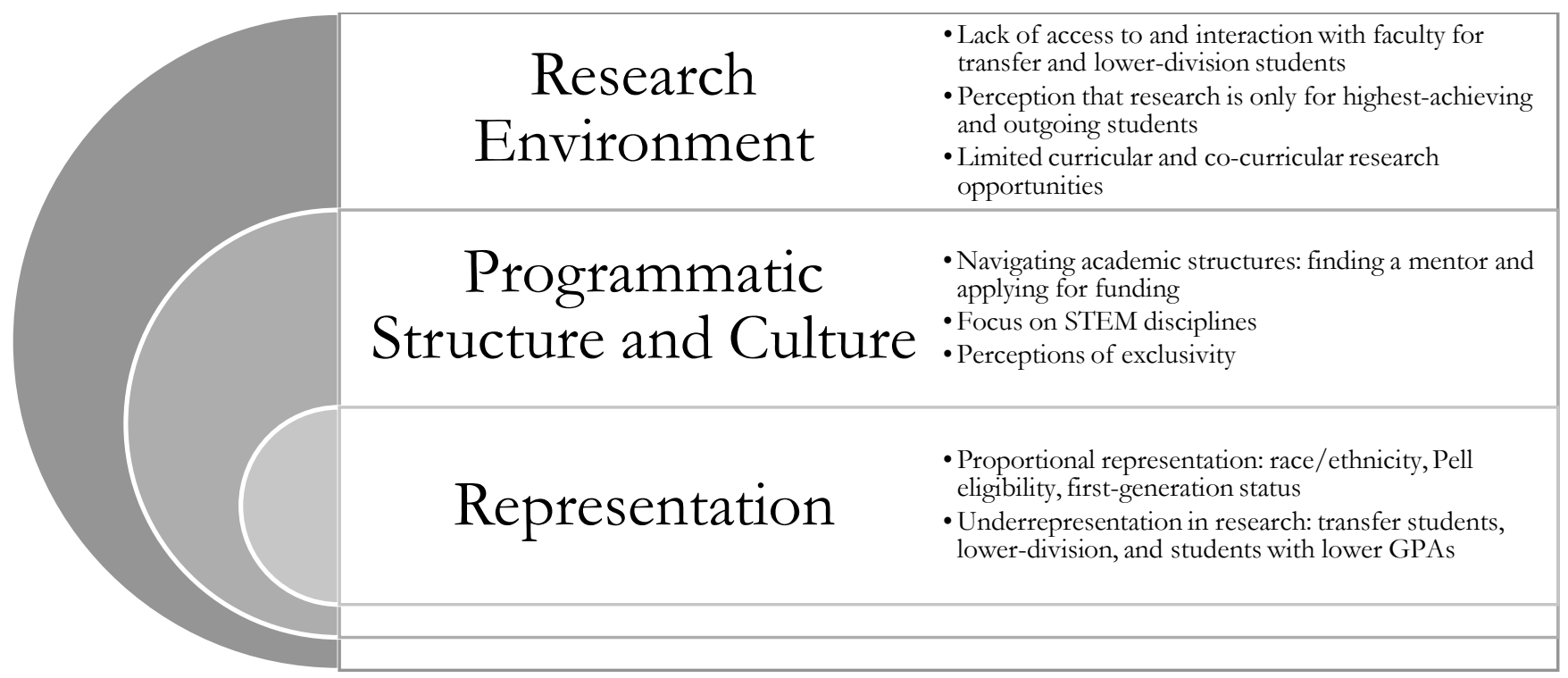

Figure 9: Findings within the Conceptual Model of Inclusivity

\section{Representation}

Our findings suggest that the basic level of representational diversity is met as the population of researchers was proportionally similar to the campus population and to students who expressed interest in research but did not participate. This is likely due to outreach efforts and the financial support provided by grant initiatives aimed at increasing diversity in research. These Department of Education grants (e.g., the Ronald E. McNair Postbaccalaureate Achievement Program and Hispanic Serving Institution, STEM Articulation Program) are used to provide funding for undergraduate researchers, fund outreach to traditionally underrepresented populations, and fund academic positions that support students in finding research placements and facilitate professional development. These programs, along with a campus commitment to diversity, have worked to break patterns of unequal participation in research in terms of race and class (Haeger, BrckaLorenz, \& Webber, 2015). Despite the success of these efforts, transfer students were still less likely to engage in research, and a significant population of students believe that research would benefit them in their education and career goals 
but are not able to participate. These findings point to the need for the creation of more opportunities and stronger outreach to lower-division, community college, and recent transfer students.

Representation Response: Community College Apprentice Research Experience (CCARE). The community college apprenticeship program was created in 2018 in order to provide an opportunity for community college students to connect with the campus community and conduct research with university faculty before transferring. Through outreach and collaboration with local and statewide community colleges, we aim to recruit incoming transfer students and students who intend to transfer to a 4-year college. Once selected, students participate in a 9-10 week research experience, are connected with appropriate university resources (e.g., staff at the Transfer Student Success Center), and are highly encouraged to live with their cohort of CCARE students on campus. The summer concludes with a summer research symposium where all undergraduate researchers present their findings. In 2019, this symposium included 25 oral presentations and over 80 posters from students conducting research at the university and regional research partners.

Representation Response: Course-based Undergraduate Research Experiences (CURE). CUREs are often touted as a way to increase opportunities for students to engage in research (Nikolova, Eddins, \& Williams, 1997; Wilson, Howitt, \& Higgins, 2015). The creation of CUREs targeting recent transfer students and lower-division students would provide earlier contact with tenure-track faculty, as well as an introductory research experience for more students. A book titled "Course-based Undergraduate Research Educational Equity and High-Impact Practice" outlines several initiatives that target students in lower division courses (Hensel, 2018). For example, faculty at North Seattle College (NSC) and Central Washington University have collaborated to develop Interdisciplinary Investigation (IDI)-Lab for first-year community college students with an emphasis on investigative skills. In their chapter titled "A High-throughput model for CUREs for the first two years of Chemistry and Biology," the authors discuss the creation of IDI-Lab and report student self-assessed gains (e.g., an increased confidence in science communication) as determined via the CURE survey (Lopatto 2004). We have created a CURE Faculty Fellows Program in order to support faculty to develop courses that engage students in authentic research experiences. This program is currently in its third year and is funded by the Provost and a U.S. Department of Education Hispanic-Serving Institution: STEM Articulation Grant. Like the creators of IDI-Lab, our goal is to engage students in collaborative, authentic research experiences and to encourage the integration of CUREs across departments. In order to support faculty in developing course-based research experiences, the CURE Faculty Fellows programs provides up to $\$ 5,760$ for 72 hours of work (based on summer salary rate) provided by a Department of Education Hispanic-Serving Institution (HSI) Division grant and an institutional commitment through the Provost's Office. During this funded time, faculty work together in a community of practice to develop new courses or redesign existing courses to include research experiences. In addition to providing time for course development, campuses should consider how else to incentivize the inclusion of research in courses, including how it is documented and evaluated in tenure and promotion consideration.

\section{Program Structure and Culture}

Looking beyond representation, we found a number of barriers to full inclusion in research. At the programmatic level, navigating academic structures, like applying for funding through UROC or finding a research placement with faculty on campus, were significant barriers to many students. Students requested a centralized way to learn about research happening on campus instead of having to email individual faculty or only having access to faculty that they currently had classes with. Students also wanted explicit and clear information about the availability of funding for research and the application process. Furthermore, even though the university offers a number of funded

Journal of the Scholarship of Teaching and Learning, Vol. 21, No. 1, April 2021. josotl.indiana.edu 
opportunities, many students are unaware of them. Students also felt that UROC and research in general were intimidating, exclusive spaces.

Program Structure and Culture Response: Scholar Spotlights. UROC is collaborating with Dr. Corin Slown, Assistant Professor in the College of Science, to integrate "Scientist Spotlights" in several lower-division STEM courses. "Scientist Spotlights" are metacognitive homework assignments that highlight counter-stereotypical scientists. Schinske et. al. (2017) demonstrated that students who completed these spotlights found personal connections with the highlighted scientists and described scientists with counter-stereotypical attributes. These data were exceptionally encouraging because these students were enrolled in an introductory biology course at a diverse community college (De Anza College).

\section{Research Environment}

The perception of exclusivity was a barrier for research with the UROC and in general. Faculty also mentioned that inviting students into research has inherent bias. For example, faculty reaching out to students in class about participating in research likely favors students who are more outgoing, who resemble or are otherwise more relatable to faculty, and who participate more actively in class (Aikens et al., 2016; Haeger \& Fresquez, 2016). Thus, students whose cultures show respect by listening quietly and attentively may be frequently overlooked, and faculty may not realize the implicit biases affecting the students. Students also frequently talked about research only being for the highest-achieving students and for students with concrete academic and career plans. Thus, students that did not think their GPAs were strong enough and/or that lacked clear goals opted out of research. Shifting the norms about who does research and emphasizing that exploration and failure are part of the research process can help shift this expectation.

Research Environment Response: The Game of Undergraduate Research. Games such as "Fair Play" (Guitierrez et al., 2014) and "REAL LIVES" (Bachen, Hernandez-Ramos, \& Raphael, 2012) have been used to foster empathy by allowing players to inhabit the lives of other individuals. The creators of "Fair Play" show a reduced implicit race bias in players that had high empathy for Jamal, a black graduate student (Guitierrez et al., 2014). We have developed "The Game of Undergraduate Research" (see Appendix I) in order to share research findings from the present study with faculty regarding the barriers to participation in UR or their CUREs. This faculty development activity is an adaptation of "The Game of Life", a board game where players read through scenarios and roll dice to see which outcome their character will experience. The characters were created from common demographic characteristics (e.g., being a first-generation college student or a student whose parents went to college) and situational barriers (e.g., having transportation issues, child care responsibilities, or long commutes). Both the UR and CURE version of the game have participants walk through scenarios in order to explore potential experiences of undergraduates. The CURE version of the game has been piloted in the first two iterations of a CURE Faculty Fellows Program, and the UR version was played by approximately 200 faculty and staff at national conferences and at the university. The CURE Faculty Fellows Program is facilitated yearly with small (10-15) cohorts of faculty by UROC staff and faculty partners. $75 \%$ of faculty in the $2019-2020$ cohort said that their participation in the game moderately or significantly influenced their plans to develop their courses. We were also encouraged to see faculty processing how privilege can intersect with undergraduate research opportunities and CURE structures in their reflections. Many faculty were struck by how factors like socioeconomic status, transfer status, or being a parent/caretaker can "stack the deck" and create barriers for students; as one faculty noted, "People with different levels of privilege have different sized margins that allow success or failure. These margins are out of peoples' control" (Faculty survey). Another faculty reflected on the ways that intersecting identities and life circumstances can impact student experiences: "It

Journal of the Scholarship of Teaching and Learning, Vol. 21, No. 1, April 2021.

josotl.indiana.edu 
became apparent that some students are very privileged and rarely experience negative results from 'Life.' The game reminded me to take student identity into consideration when setting up the CURE project" (Faculty survey). Instructions for facilitation and the game itself are available in Appendix I.

\section{Conclusion}

This research illustrates the ways that research environment, programmatic structure, and culture can influence inclusivity in research. Representational diversity is a crucial foundation, but even when equal representation is achieved, institutions should work to reduce barriers for new-majority students to move towards full inclusion in research. These barriers will be unique to each institution, and mixedmethods studies provide the qualitative and quantitative data needed to plan student voice and datainformed interventions. As we continue to scale-up undergraduate research experiences, it is crucial to critically evaluate not only who has access to research experiences, but also how inclusive these experiences are for new-majority students.

\section{Acknowledgements}

Research reported in this paper was supported by the Department of Education McNair Scholars Program under award number P031C160221 and the Department of Education Hispanic-Serving Institution (HSI) Division under award number P217A170213 through California State University, Monterey Bay's Undergraduate Research Opportunity Center.

\section{Appendix}

\section{Appendix 1. The Game of Undergraduate Research. Game Facilitation Notes}

The game of UR is conducted in groups of four and requires one die per group. Each participant is handed a copy of the game and rolls the die to determine who will be Lucas, Christopher, Deborah, and Lissette. The participant who rolls the lowest number will facilitate the group and be the student named Lucas throughout the duration of the game. The game includes 5 challenges, and it is the facilitator's job to read each challenge and make sure each character rolls to determine their outcome. After each challenge, the outcome $(-1$ or +1$)$ is recorded for each student identity. Each student identity has a different probability of success (e.g., Christopher is less likely to succeed than Lissette).

The participants usually need guidance within the first 10 minutes to ensure they are recording the outcomes of each student and understand how to determine said outcome. Once the participants are orientated, the game moves quickly. We suggest having participants pause to reflect after challenge 3 or 4. Reflection questions such as "How is Christopher doing?" and "How are you feeling as Lucas?" have helped participants discuss privilege and the inequities experienced by their students. Challenge 5 concludes the game, and participants are prompted to record and discuss final outcomes (e.g., grade in the CURE or acquiring an undergraduate research experience).

The final outcome is different for student identities that get less than two positive outcomes, at least two positive outcomes, or at least three positive outcomes. Usually, Lucas has the most success while Deborah has the least success, and participants with these characters have polarized emotions about their experiences. The reactions of the participants give the game facilitators the material needed to moderate a discussion about privilege, equity, and strategies to make UR or CUREs more equitable. If multiple groups of four play the game, it is interesting to record the outcomes of each student identity in each group and discuss the similarities and differences between how participants felt as each student. 


\section{Appendix 2. The Game of Mentored Undergraduate Research.}

Overview: This game is designed to walk you through scenarios that allow the exploration of the potential student experience within undergraduate research. Yourgoal as a student is to obtain an undergraduate research experience and prepare for your future.

The Facilitator: Roll to see who the facilitator is (lowest number is facilitator and Lucas). Assign student identities around the circle. Your job as the facilitator is to read each scenario/challenge.

Each student will roll and then read their outcome based on their roll.

Be sure to announce and record your outcome (facilitator: circle + for positive or - negative) to the group before moving to the next person.

\section{Positive or Negative Outcomes}

\begin{tabular}{|c|c|c|c|c|c|c|c|c|c|}
\hline & & $\begin{array}{l}\text { ge 1: } \\
\text { Out } \\
\text { h }\end{array}$ & & $\begin{array}{l}\text { age 2: } \\
\text { In }\end{array}$ & $\begin{array}{l}\mathrm{Ch} \\
\mathrm{Fic}\end{array}$ & gerk 3 : & $\begin{array}{l}\text { Ch } \\
\text { Pre } \\
\text { you }\end{array}$ & $\begin{array}{l}\text { ige 4: } \\
\text { ing } \\
\text { esearch }\end{array}$ & $\begin{array}{l}\text { Total Number } \\
\text { of Positive } \\
\text { Outcomes }\end{array}$ \\
\hline Lucas & + & - & + & - & + & - & + & - & \\
\hline Christopher & + & - & + & - & + & - & + & - & \\
\hline Deborah & + & - & + & - & + & - & + & - & \\
\hline Lissette & + & - & + & - & + & - & + & _ & \\
\hline
\end{tabular}

\section{Student Identities}

You are a student at Western University which is a medium sized public school with a centralized Undergraduate Research Opportunities Center (UROC).

Lucas is a White male from a middle-class family in New York. He is involved in intramural sports and a club on campus. He typically gets B's and C's. In order to get a positive result he must roll a $1,2,3,4$, or 5 .

Christopher is an African American male, is from a low-income neighborhood in a rural area 25 miles from Western University. He lives at home and commutes to campus with a classmate. He marches in the school band and is an honor roll student. In order to get a positive outcome he must only roll a 4 or 5 . 
Deborah is an Asian American female. She is a single parent of two. She lives in an off-campus apartment 2 miles from Western University. She works two jobs and typically gets C's in school. In order to get a positive outcome she must only roll a 6 .

Lissette is from a low-income family and is from Los Angeles, California. She is Latina and has undocumented parents. She is involved in many of the school organizations on campus and is typically a B student. In order to get a positive result she must roll only a 2, 3, or 4 .

\section{Challenge 1: Finding Out About Research Opportunities}

You are thinking about what to do this summer and want to find an experience to build skills that will help you in your future career. You hear another student talking about doing research on campus over the summer. That sounds exciting to you but you don't know where to start. There are no more undergraduate research positions in the lab your friend works in and you feel a little discouraged about finding an opportunity.

What happens to your character? Roll the dice to find out. 


\section{Challenge 1: Finding Out About Research}

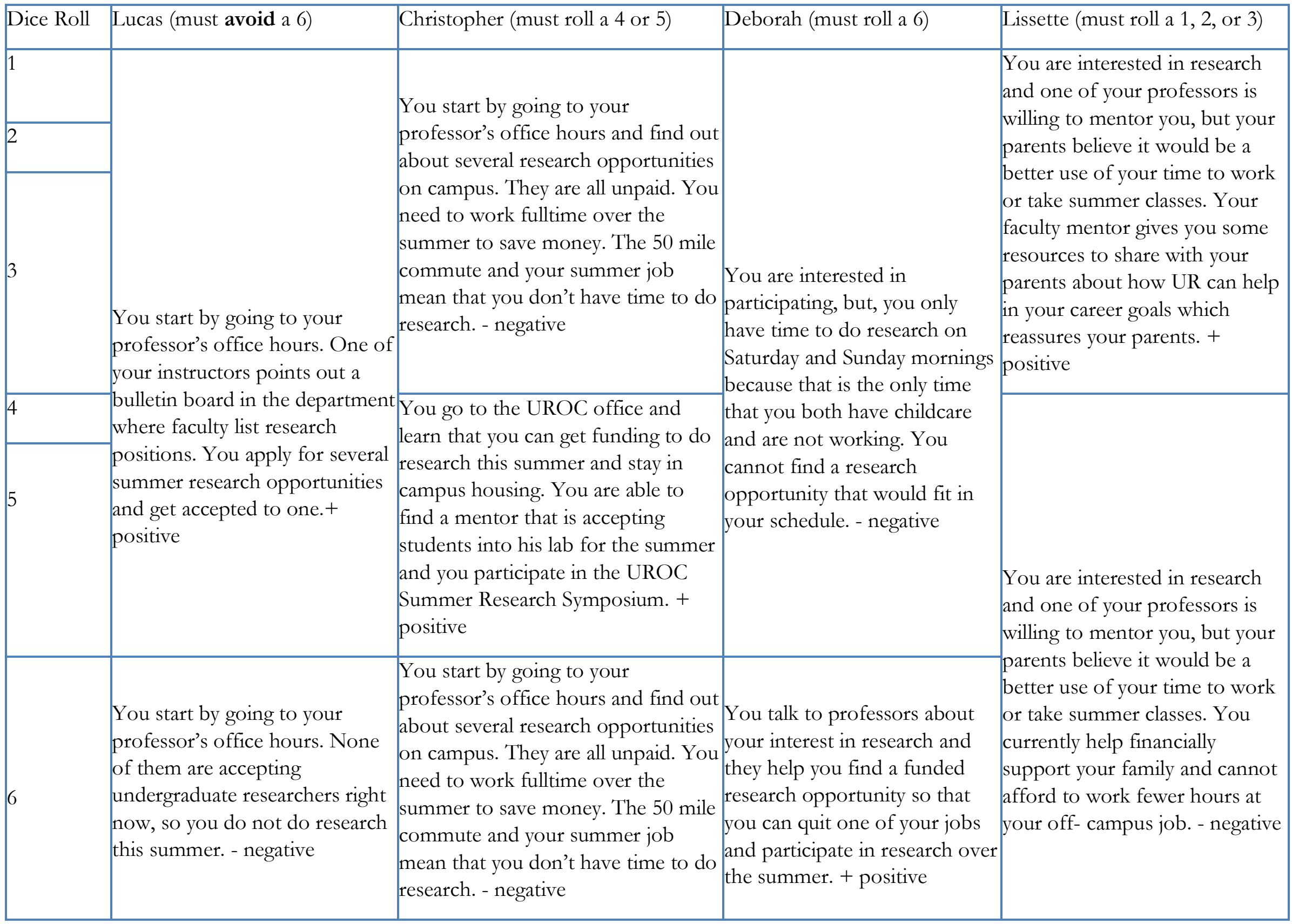




\section{Challenge 2: Getting In}

It is the middle of the semester, and you are performing extremely well on all of your coursework in your favorite class. One day, your instructor announces that he is conducting research and looking for undergraduate researchers for the summer. He stated that he is looking for the "best" students to join his research team. This is of extreme interest to you; however, you have no experience in research.

What happens to your character? Roll the dice to find out. 


\section{Challenge 2: Getting In}

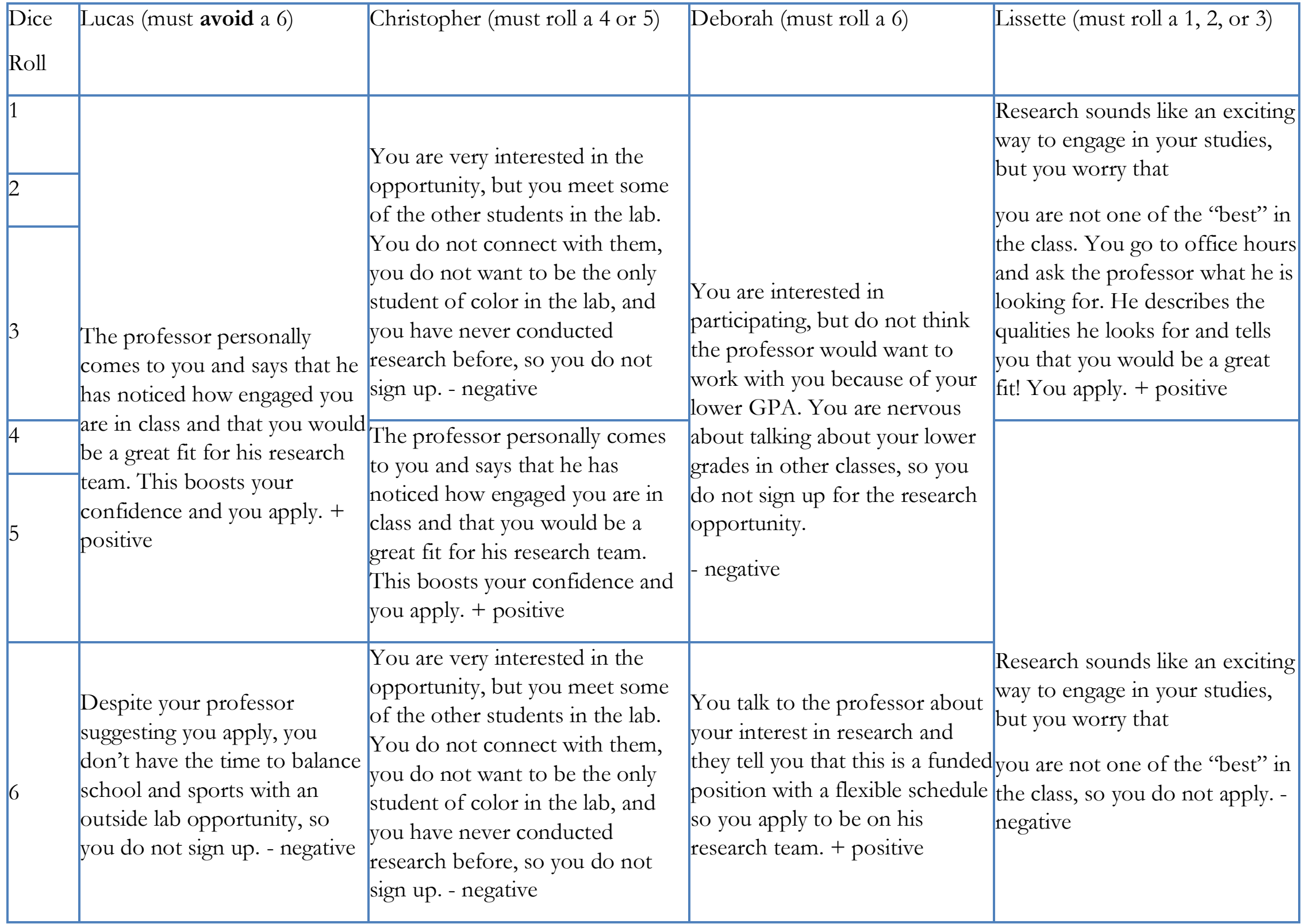




\section{Challenge 3: Field Work}

You are in a course-based undergraduate research experience. You and your fellow classmates have already gone through a boot camp that highlighted and taught you some relevant basic research skills. You and your classmates are excited and are surprised that people actually do research in your field. Your instructor announces that you all will be meeting on Friday mornings, off-campus, in a nature reserve 15 miles from campus to gather data for a group research project. This project counts towards two thirds of your final grade. You have never been to the location and are uneasy about how you will get there.

What happens to your character? Roll the dice to find out. 


\section{Challenge 3: Field Work}

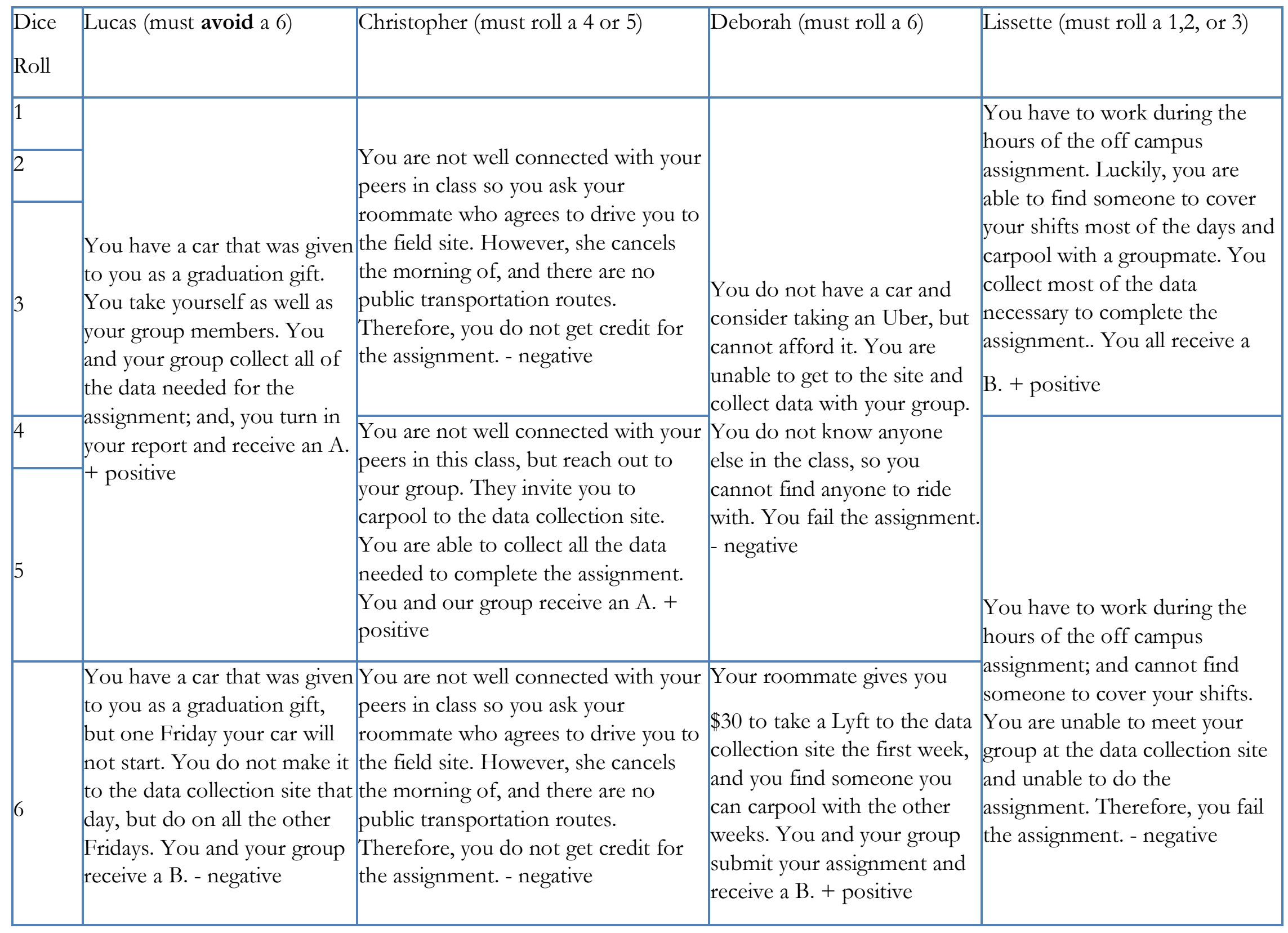




\section{Challenge 4: Presenting your Research}

You are in a capstone/ senior level course-based research experience. Your instructor announces that the final will be a presentation at a conference in your field which is being hosted on your campus this year. Your group has the opportunity to present a poster at the conference. The symposium organizers are giving out awards for the best presentations and the instructor has agreed to award 5\% points on top of the final grade of award winners. You are right on the edge between letter grades are excited to showcase what you and your group have accomplished. You are excited about this professional opportunity but also nervous because you have never been to a professional conference or given a research poster presentation before.

What happens to your character? Roll the dice to find out. 


\section{Challenge 4: Presenting your Research}

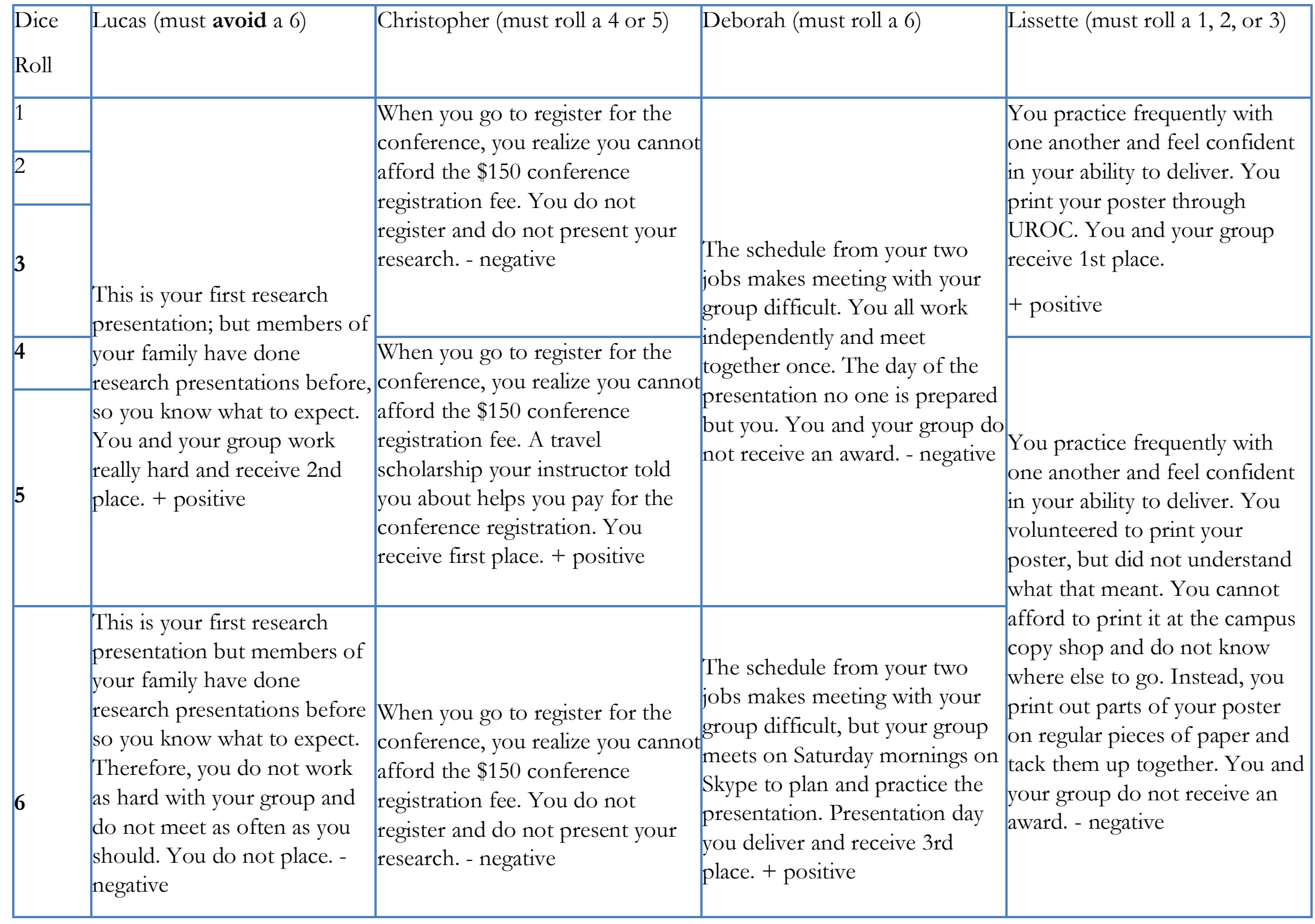




\section{Summary of Outcomes}

Characters with less than 2 positive outcomes: You have no interest in pursuing undergraduate research. In fact, you are not sure what research looks like and why people do research. Furthermore, you feel that research is not for people like you.

Characters with at least 2 positive outcomes: You participate in an undergraduate research opportunity but have no interest in continuing to pursue it. You feel that only extremely intelligent people are able to do research, and doubt that you are one of those people.

Characters with at least 3 positive outcomes: You plan to pursue other research opportunities on campus and are exploring careers related to your research interests. There are so many opportunities in your field and you cannot wait to contribute; you sign up for research opportunities within your field of study. 


\section{The Game of Course-based Undergraduate Research Experiences}

Overview: This game is designed to walk you through scenarios that allow the exploration of the potential student experience within undergraduate research. Yourgoal as a student is to obtain a strong grade in your class, participate in an undergraduate research experience, and prepare for your future.

The Facilitator: Roll to see who the facilitator is (lowest number is facilitator and Lucas). Assign student identities around the circle. Your job as the facilitator is to read each scenario/challenge.

Each student will roll and then read their outcome based on their roll.

Be sure to announce and record your outcome (facilitator: circle + for positive or - negative) to the group before moving to the next person.

\section{Positive or Negative Outcomes}

\begin{tabular}{|c|c|c|c|c|c|c|c|c|c|c|c|}
\hline \multirow{2}{*}{ Lucas } & \multicolumn{2}{|c|}{$\begin{array}{l}\text { Challenge 1: Field } \\
\text { Work }\end{array}$} & \multicolumn{2}{|c|}{$\begin{array}{l}\text { Challenge 2: } \\
\text { Group Work }\end{array}$} & \multicolumn{2}{|c|}{$\begin{array}{l}\text { Challenge 3: } \\
\text { Unexpected } \\
\text { Results }\end{array}$} & \multicolumn{2}{|c|}{$\begin{array}{l}\text { Challenge 4: } \\
\text { Continuing } \\
\text { Research }\end{array}$} & \multicolumn{2}{|c|}{$\begin{array}{l}\text { Challenge 5: } \\
\text { Presenting your } \\
\text { Research }\end{array}$} & \multirow[t]{2}{*}{$\begin{array}{l}\text { Total Number of } \\
\text { Positive } \\
\text { Outcomes }\end{array}$} \\
\hline & + & - & + & - & + & - & + & - & + & - & \\
\hline Christopher & + & - & + & - & + & - & + & - & + & - & \\
\hline Deborah & + & - & + & - & + & - & + & - & + & - & \\
\hline Lissette & + & - & + & - & + & - & + & - & + & - & \\
\hline
\end{tabular}




\section{Student Identities}

You are a student at Western University which is a medium sized public school with a centralized Undergraduate Research Opportunities Center (UROC).

Lucas is a White male from a middle-class family in New York. He is involved in intramural sports and a club on campus. He typically gets B's and C's. In order to get a positive result he must roll a $1,2,3,4$, or 5 .

Christopher is an African American male, is from a low-income neighborhood in a rural area 25 miles from Western University. He lives at home and commutes to campus with a classmate. He marches in the school band and is an honor roll student. In order to get a positive outcome he must only roll a 4 or 5 .

Deborah is an Asian American female. She is a single parent of two. She lives in an off-campus apartment 2 miles from Western University. She works two jobs and typically gets C's in school. In order to get a positive outcome she must only roll a 6 .

Lissette is from a low-income family and is from Los Angeles, California. She is Latina and has undocumented parents. She is involved in many of the school organizations on campus and is typically a B student. In order to get a positive result she must roll only a 2,3 , or 4 . 


\section{Challenge 1: Field Work}

You are in a course-based undergraduate research experience. You and your fellow classmates have already gone through a boot camp that highlighted and taught you some relevant basic research skills. You and your classmates are excited and are surprised that people actually do research in your field.

Your instructor announces that you all will be meeting on Friday mornings, off-campus, in a nature reserve 15 miles from campus to gather data for a group research project. This project counts towards a third of your final grade. You have never been to the location and are uneasy about how you will get there.

What happens to your character? Roll the dice to find out. 


\section{Challenge 1: Field Work}

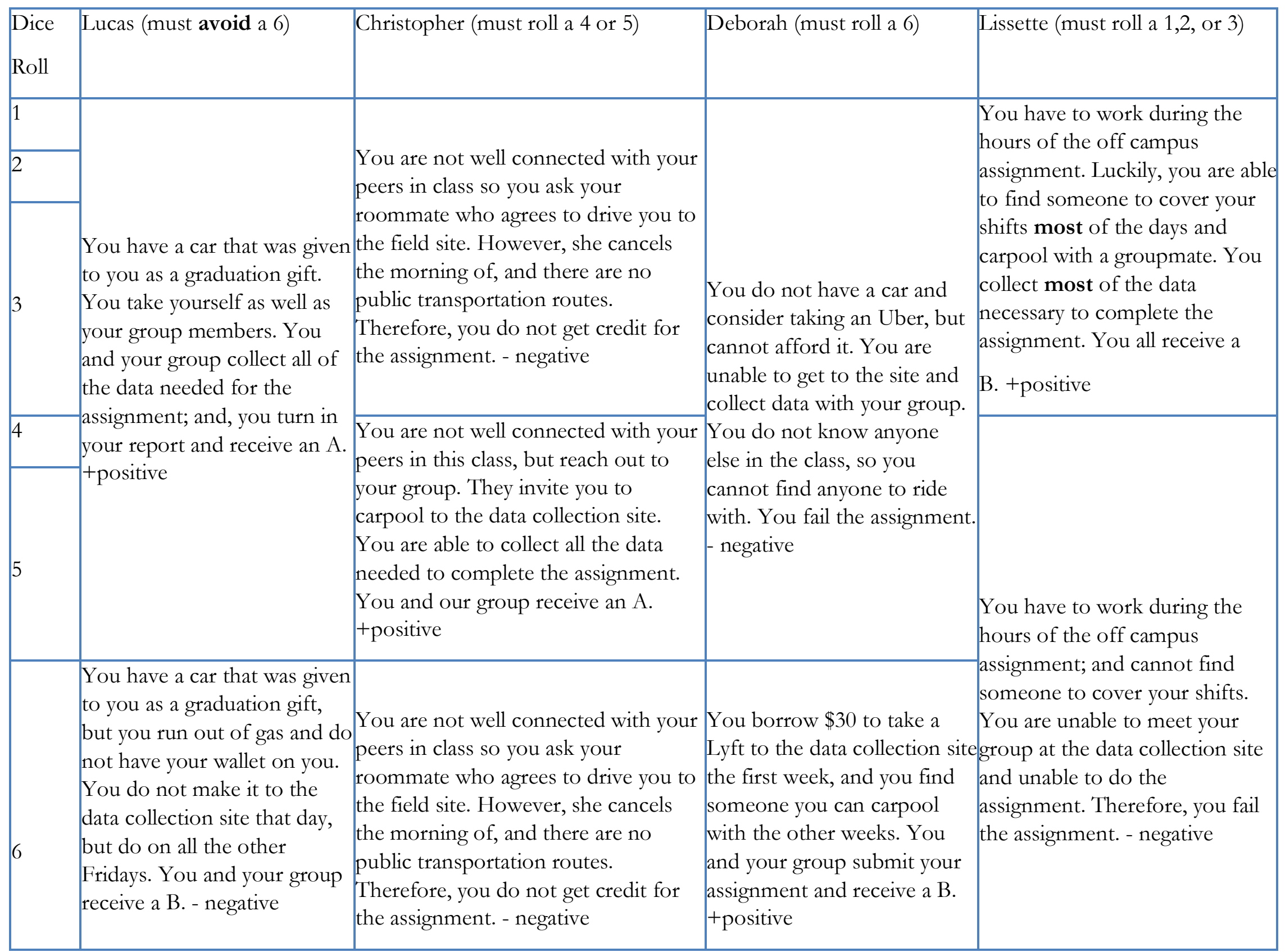




\section{Challenge 2: Group Work}

It is the middle of the semester and your group has a lot of data to analyze before the midterm. Your instructor informs you that there will be questions on the midterms that involve interpreting results and you need to meet with your group to practice. The group decides that the best time to meet is outside of class. Your group will also submit your group progress report at the end of this meeting.

What happens to your character? Roll the dice to find out. 
Haeger, White, Martinez, and Velasquez

Challenge 2: Group Work

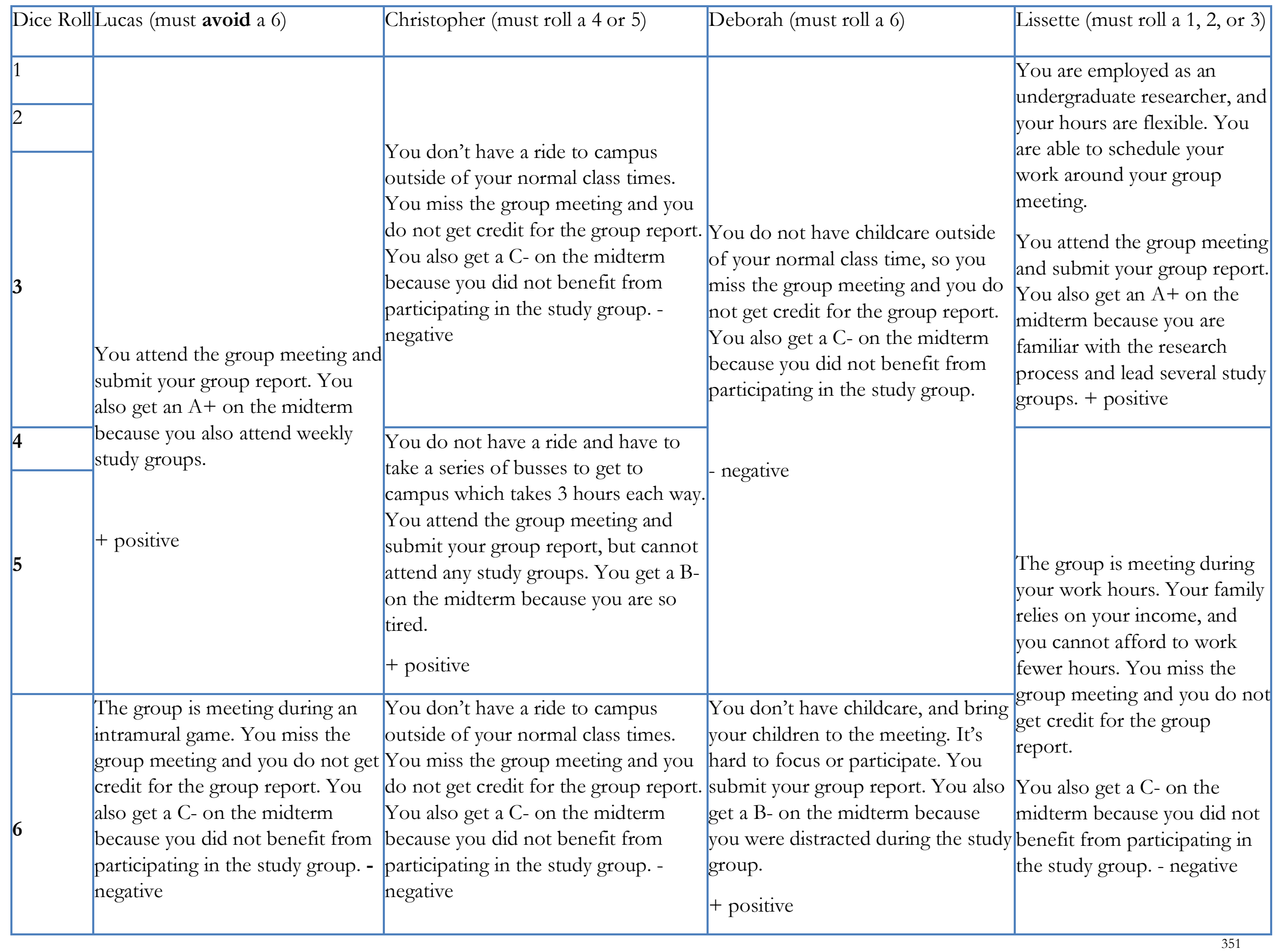

Journal of the Scholarship of Teaching and Learning, Vol. 21, No. 1, April 2021. josotl.indiana.edu 


\section{Challenge 3: Unexpected Results}

You and your group have just completed the third iteration of a key experiment in your class, and you have some unexpected results that do not align with your prediction. Your instructor said that your results need to be repeatable and only two of the iterations match in terms of overall conclusion. Your group does not have the time to repeat the experiment before the final lab report is due.

What happens to your character? Roll the dice to find out. 
Challenge 3: Unexpected Results

\begin{tabular}{|c|c|c|c|c|}
\hline $\begin{array}{l}\text { Dice } \\
\text { Roll }\end{array}$ & Lucas (must avoid a 6) & Christopher (must roll a 4 or 5) & Deborah (must roll a 6) & Lissette (must roll a 1,2 , or 3 ) \\
\hline 2 & $\begin{array}{l}\text { Your group talks to the } \\
\text { instructor about your } \\
\text { conflicting results. The } \\
\text { instructor reiterates that } \\
\text { negative results are still results } \\
\text { and suggests that you include } \\
\text { all of the results in your final } \\
\text { lab report. The instructor also } \\
\text { discusses the results with the }\end{array}$ & $\begin{array}{l}\text { Your group submits the report } \\
\text { without addressing the differences } \\
\text { in results and receives a B-. }\end{array}$ & $\begin{array}{l}\text { After talking to other classmates } \\
\text { about their results, you feel } \\
\text { embarrassed because you did } \\
\text { not get the "correct answer". }\end{array}$ & $\begin{array}{l}\text { Your group talks to the TA about your } \\
\text { conflicting results. The TA reiterates that } \\
\text { negative results are still results and suggests } \\
\text { that you include all of the results in your final } \\
\text { lab report. The TA also discusses the results } \\
\text { with the group and they include an explanation } \\
\text { of why the results conflict. The instructor is } \\
\text { impressed with the thoroughness of the lab } \\
\text { report and you receive an A+.+ positive }\end{array}$ \\
\hline 4 & $\begin{array}{l}\text { group and they include an } \\
\text { explanation of why the results } \\
\text { conflict. The instructor is } \\
\text { impressed with the } \\
\text { thoroughness of the lab } \\
\text { report and you receive an A+. } \\
+ \text { positive }\end{array}$ & $\begin{array}{l}\text { Your group attends a } \\
\text { Supplemental Instruction session } \\
\text { to talk about your conflicting } \\
\text { results. The SI reiterates that } \\
\text { negative results are still results and } \\
\text { suggests that you include all of the } \\
\text { results in your final lab report. } \\
\text { You receive an A- on the lab } \\
\text { report.+ positive }\end{array}$ & $\begin{array}{l}\text { You decide to finish the report } \\
\text { on your own and fabricate the } \\
\text { last replicate. } \\
\text { The instructor discerns that you } \\
\text { falsified some of your results } \\
\text { and you receive no credit for } \\
\text { the final lab report. } \\
\text { negative }\end{array}$ & \multirow[b]{2}{*}{$\begin{array}{l}\text { After talking to other classmates about their } \\
\text { results, you feel embarrassed because you did } \\
\text { not get the "correct answer". You decide to } \\
\text { finish the report on your own and fabricate the } \\
\text { last replicate. The instructor discerns that you } \\
\text { falsified some of your results and you receive } \\
\text { no credit for the final lab report. }\end{array}$} \\
\hline 6 & $\begin{array}{l}\text { Your group submits the } \\
\text { report without addressing the } \\
\text { differences in results and } \\
\text { receives a B-. }\end{array}$ & $\begin{array}{l}\text { Your group submits the report } \\
\text { without addressing the differences } \\
\text { in results and receives a B-. }\end{array}$ & $\begin{array}{l}\text { You talk to a friend in your } \\
\text { major about your conflicting } \\
\text { results. They say that negative } \\
\text { results are still results and } \\
\text { suggests that you include all of } \\
\text { the results in your final lab } \\
\text { report. The instructor is } \\
\text { impressed with the way you } \\
\text { addressed the discrepancies in } \\
\text { the lab report and you receive } \\
\text { an B+.+ positive }\end{array}$ & \\
\hline
\end{tabular}




\section{Challenge 4: Continuing Research after the Class}

It is the middle of the semester, and you are performing extremely well on all of your coursework in your CURE class. One day, your instructor announces that he is continuing this research over the summer and looking for undergraduate researchers to continue the project. He stated that he is looking for the "best" students to join his research team. This is of extreme interest to you.

What happens to your character? Roll the dice to find out. 
Haeger, White, Martinez, and Velasquez

\section{Challenge 4: Continuing Research after the Class}

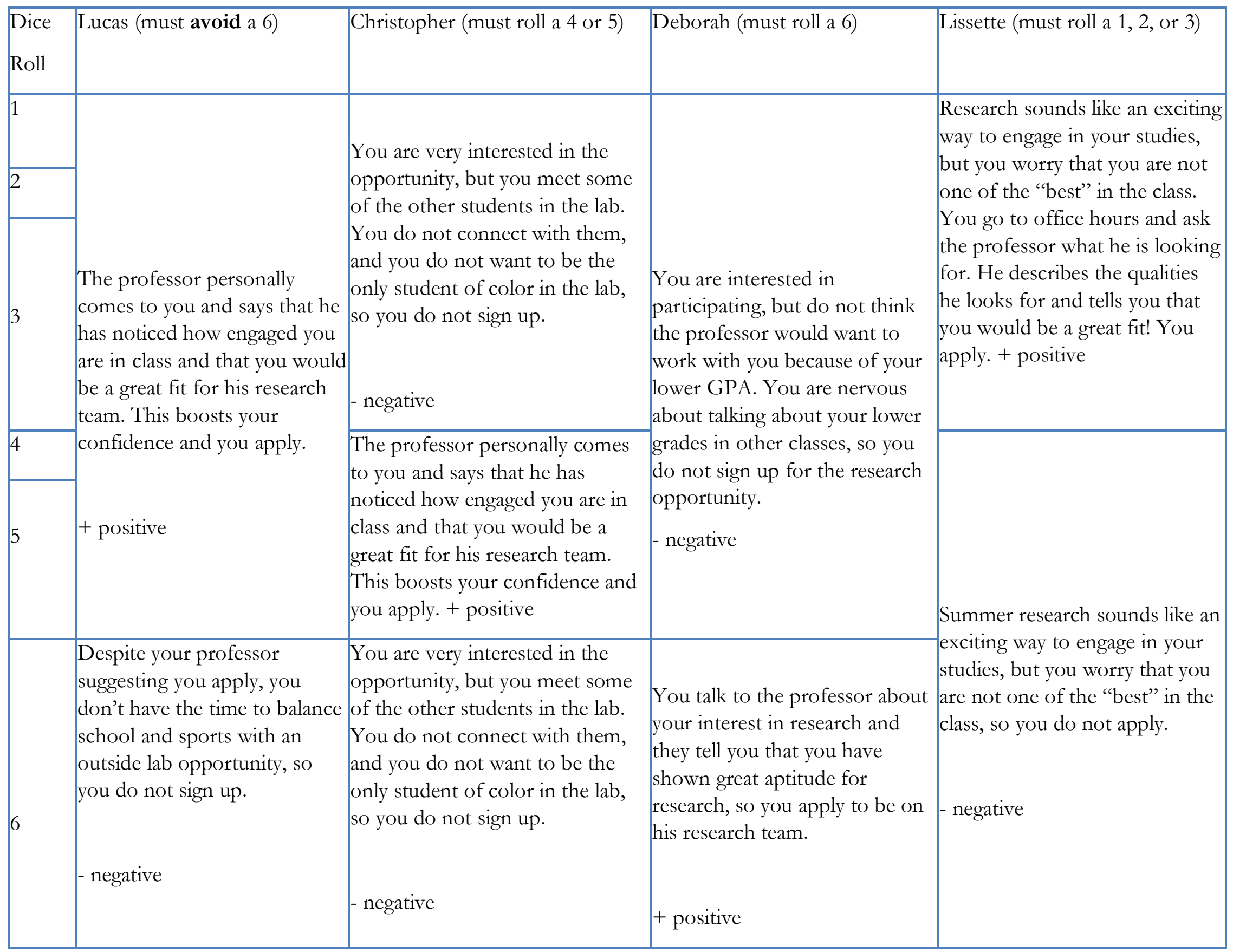




\section{Challenge 5: Presenting your Research}

You are in a capstone/ senior level course-based research experience. Your instructor announces that the final will be a presentation at a conference in your field which is being hosted on your campus this year. Your group has the opportunity to present a poster at the conference. The symposium organizers are giving out awards for the best presentations and the instructor has agreed to award 5\% points on top of the final grade of award winners. You are right on the edge between letter grades are excited to showcase what you and your group have accomplished. You are excited about this professional opportunity but also nervous because you have never been to a professional conference or given a research poster presentation before.

What happens to your character? Roll the dice to find out. 


\section{Challenge 5: Presenting your Research}

\begin{tabular}{|c|c|c|c|c|}
\hline $\begin{array}{l}\text { Dice } \\
\text { Roll }\end{array}$ & Lucas (must avoid a 6) & Christopher (must roll a 4 or 5) & Deborah (must roll a 6) & Lissette (must roll a 1, 2, or 3) \\
\hline 1 & \multirow{4}{*}{$\begin{array}{l}\text { This is your first research } \\
\text { presentation; but members of } \\
\text { your family have done } \\
\text { research presentations before, } \\
\text { so you know what to expect. } \\
\text { You and your group work } \\
\text { really hard and receive } 2 \text { nd } \\
\text { place. }\end{array}$} & \multirow{3}{*}{$\begin{array}{l}\text { When you go to register for the } \\
\text { conference, you realize you cannot } \\
\text { afford the } \$ 150 \text { conference } \\
\text { registration fee. You do not } \\
\text { register and do not present your } \\
\text { research. - negative }\end{array}$} & \multirow{4}{*}{$\begin{array}{l}\text { The schedule from your two } \\
\text { jobs makes meeting with your } \\
\text { group difficult. You all work } \\
\text { independently and meet } \\
\text { together once. The day of the } \\
\text { presentation no one is prepared } \\
\text { but you. You and your group do } \\
\text { not receive an award. - negative }\end{array}$} & \multirow{3}{*}{$\begin{array}{l}\text { You practice frequently with } \\
\text { one another and feel confident } \\
\text { in your ability to deliver. You } \\
\text { print your poster through } \\
\text { UROC. You and your group } \\
\text { receive 1st place. } \\
+ \text { positive }\end{array}$} \\
\hline 2 & & & & \\
\hline 3 & & & & \\
\hline 4 & & $\begin{array}{l}\text { When you go to register for the } \\
\text { conference, you realize you cannot } \\
\text { afford the } \$ 150 \text { conference } \\
\text { registration fee. A travel } \\
\text { scholarship your instructor told } \\
\text { you about helps you pay for the } \\
\text { conference registration. You } \\
\text { receive first place. }+ \text { positive }\end{array}$ & & \multirow{2}{*}{$\begin{array}{l}\text { You practice frequently with } \\
\text { one another and feel confident } \\
\text { in your ability to deliver. You } \\
\text { volunteered to print your } \\
\text { poster, but did not understand } \\
\text { what that meant. You cannot } \\
\text { afford to print it at the campus } \\
\text { copy shop and do not know } \\
\text { where else to go. Instead, you } \\
\text { print out parts of your poster } \\
\text { on regular pieces of paper and } \\
\text { tack them up together. You and } \\
\text { your group do not receive an } \\
\text { award. }\end{array}$} \\
\hline 6 & $\begin{array}{l}\text { This is your first research } \\
\text { presentation but members of } \\
\text { your family have done } \\
\text { research presentations before } \\
\text { so you know what to expect. } \\
\text { Therefore, you do not work } \\
\text { as hard with your group and } \\
\text { do not meet as often as you } \\
\text { should. You do not place. - } \\
\text { negative }\end{array}$ & $\begin{array}{l}\text { When you go to register for the } \\
\text { conference, you realize you cannot } \\
\text { afford the } \$ 150 \text { conference } \\
\text { registration fee. You do not } \\
\text { register and do not present your } \\
\text { research. - negative }\end{array}$ & $\begin{array}{l}\text { The schedule from your two } \\
\text { jobs makes meeting with your } \\
\text { group difficult, but your group } \\
\text { meets on Saturday mornings on } \\
\text { Skype to plan and practice the } \\
\text { presentation. Presentation day } \\
\text { you deliver and receive 3rd } \\
\text { place. } \\
+ \text { positive }\end{array}$ & \\
\hline
\end{tabular}




\section{Summary of Outcomes}

Characters with 2 positive outcomes or less: You receive a C- or lower in the class, and have no interest in pursuing undergraduate research after this course. In fact, you are not sure what research looks like and why people do research. Furthermore, you feel that research is not for people like you.

Characters with at least 3 positive outcomes: You receive a B in the CURE but have no interest in continuing to pursue research. You feel that only extremely intelligent people are able to do research, and doubt that you are one of those people.

Characters with at least 4 positive outcomes: You receive an A- or higher in the CURE and plan to pursue other research opportunities on campus. You are also exploring careers related to your research interests. There are so many opportunities in your field and you cannot wait to contribute. 


\section{References}

Ahmed, S. (2012). On being included: Racism and diversity in institutional life. Durham: Duke University Press.

Aikens, M. L., Sadselia, S., Watkins, K., Evans, M., Eby, L. T., \& Dolan, E. L. (2016). A social capital perspective on the mentoring of undergraduate life science researchers: An empirical study of undergraduate-postgraduate-faculty triads. CBE Life Sciences Education, 15(2). doi.org/10.1187/cbe.15-10-0208

Alexander, J. M. (2005). Pedagogies of crossing, meditations on feminism, sexual politics, memory, and the sacred. Durham: Duke University Press.

Ali, S. (2009). Black feminist praxis: Some reflections no pedagogies and politics in higher education. Race, Ethnicity, and Education, 12(1), 79-66. doi.org/10.1080/13613320802650998

Bachen, C., Hernández-Ramos, P., \& Raphael, C. (2012). Simulating REAL LIVES. Simulation \& Gaming, 43(4) 437-60. https:/ / doi.org/10.1177/1046878111432108.

BrckaLorenz, A., Duran, A., \& Haeger, H. (2020). Culturally engages courses and campuses for LGBQ+ issues. Journal of Diversity in Higher Education doi.org/10.1037/dhe0000177.

CSUMB, Institutional Assessment and Research. (2020) Enrollment fast facts (most recent term). Retrieved from https://csumb.edu/iar/enrollment-fast-facts-most-recent-term CSUMB.

Chang, M. J., Sharkness, J., Hurtado, S., \& Newman, C. B. (2014). What matters in college for retaining aspiring scientists and engineers from underrepresented racial groups: Retaining aspiring scientists. Journal of Research in Science Teaching, 51(5), 555-580. https://doi.org/10.1002/tea.21146

Clancy, K. B. H., Nelson, R. G., Rutherford, J. N., \& Hinde, K. (2014). Survey of Academic Field Experiences (SAFE): Trainees Report Harassment and Assault. PLOS ONE, 9(7), e102172. doi.org/10.1371/journal.pone.0102172

Collins, P.H. \& Bilge, S. (2016). Intersectionality (key concepts). Cambridge: Polity Press.

Deem, R. \& Ozga, J. (1997). Women managing for diversity in a postmodern world. In C. Marshall (ed.), Feminist critical policy analysis: A perspective from postmodern secondary education. London: Falmer Press, 25-40.

Crenshaw, K. (1991). Mapping the margins: Intersectionality, identity politics, and violence against women of color. Stanford Law Review, 43(6), 1241-1299. doi.org/10.2307/1229039

Estrada, M., Hernandez, P. R., \& Schultz P. W. (2018). A longitudinal study of how quality mentorship and research experience integrate underrepresented minorities into STEM careers. CBE_Life Sciences Education 17(1). doi.org/10.1187/cbe.17-04-0066.

Gutierrez, B., Kaatz, A., Chu, S., Ramirez, D., Samson-Samuel, C., \& Carnes, M. (2014). "Fair play": A videogame designed to address implicit race bias through active perspective taking. Games for Health Journal 3(6), 371-78. https:/ / doi.org/10.1089/g4h.2013.0071.

Haeger, H., BrckaLorenz, A., \& Webber, K. (2015). Participation in undergraduate research at minority serving institutions. Perspectives on Undergraduate Research and Mentoring, 4(1). Retrieved from http://blogs.elon.edu/purm/files/2015/11/Haeger-et-al-PURM-4.1-1.pdf

Haeger, H. \& Fresquez, C. (2016). Mentoring for inclusion: The impact of mentoring on undergraduate researchers in the sciences. CBE-Life Sciences Education, 15(3), ar36. https://doi.org/10.1187/cbe.16-01-0016Hensel, N. H. (2018). Course-based undergraduate research: Educational equity and high-impact practice. Sterling, Virginia. Stylus Publishing, LLC.

Hurtado, S., Eagan, M. K., Tran, M. C., Newman, C. B., Chang, M. J., \& Velasco, P. (2011). "We do science here": Underrepresented student's interactions with faculty in different college contexts. Journal of Social Issues, 67(3), 553-579. doi.org/10.1111/j.1540-4560.2011.01714.x

Journal of the Scholarship of Teaching and Learning, Vol. 21, No. 1, April 2021.

josotl.indiana.edu 
Jones, M. T., Barlow, A. E. L., \& Villarejo, M. (2010). Importance of undergraduate research for minority persistence and achievement in biology. Journal of Higher Education, 81(1), 82-115. doi.org/10.1353/jhe. 0.0082

Kilanowski, J. (2017). Breadth of the socio-ecological model. Journal of Agromedicine, 22(4), 295-297. doi.org/10.1080/1059924X.2017.1358971

Kinzie, J., Gonyea, R., Shoup, R., \& Kuh, G. D. (2008). Promoting persistence and success of underrepresented students: Lessons for teaching and learning. New Directions for Teaching and Learning, 2008(115), 21-38. doi.org/10.1002/tl.323

Kuh, G. D. (2008). High - impact educational practices: What they are, who has access to them, and why they matter. Washington, D.C.: AAC\&U.

Mohanty, C.T. (2003). Feminism without borders: Decolonizing theory, practicing solidarity. Durham: Duke University Press.

Milem, J. F., Chang, M. J., \& Lising Antonio, A. (2005). Making diversity work on campus: A researchbased perspective. . Washington, DC: Association of American Colleges and Universities.

National Academies of Sciences, Engineering and Medicine. (2017). Undergraduate research experiences for STEM students: Successes, challenges, and opportunities. Washington, DC: The National Academies Press. doi.org/10.17226/24622

National Academy of Sciences, National Academy of Engineering, \& Institute of Medicine. (2011). Expanding underrepresented minority participation: America's science and technology talent at the crossroads. Washington, DC: The National Academies Press. doi.org/10.17226/12984

National Math + Science. (2010). Increasing the achievement and presence of under-represented minorities in STEM fields [White Paper]. Retrieved from http://nms.org/Education/TheSTEMCrisis.aspx

Nikolova Eddins, S. G., \& Williams, D. F. (1997). Research-based learning for undergraduates: a model for merger of research and undergraduate education. Journal on Excellence in College Teaching, 8(3), 77-94. ISSN: ISSN-1052-4800

Puwar, N. (2004). Space invaders: Race, gender, and bodies out of place. Oxford: Berg Press.

Robnett, R. D., Chemers, M. M., \& Zurbriggen, E. L. (2015). Longitudinal associations among undergraduates' research experience, self-efficacy, and identity. Journal of Research in Science Teaching, 52(6), 847-867. https://doi.org/10.1002/tea.21221

Schinske, J. N., Perkins, H., Snyder, A., \& Wyer, M. (2016). Scientist spotlight homework assignments shift students' stereotypes of scientists and enhance science identity in a diverse introductory science class. CBE_Life Sciences Education 15(3), 1-18. doi.org/10.1187/cbe.1601-0002

Sweeney, J. K., \& Villarejo, M. (2013). Influence of an academic intervention program on minority student career choice. Journal of College Student Development, 54(5), 534-540. https://doi.org/10.1353/csd.2013.0070

Villarejo, M., Barlow, A. E. L., Kogan, D., Veazey, B. D., \& Sweeney, J. K. (2008). Encouraging minority undergraduates to choose science careers: Career paths survey results. CBE Life Sciences Education, 7(4), 394-409. doi.org/10.1187/cbe.08-04-0018

Wilson, A., Howitt, S., \& Higgins, D. (2015). A fundamental misalignment: Intended learning and assessment practices in undergraduate science research projects. Assessment and evaluation in Higher Education, 41(6), 869-884. (doi.org/10.1080/02602938.2015.1048505 